Sherif, M. (1937). 'An experimental approach to the study of attitudes', Sociometry, $I, 90-8$.

Sherman, S. L., DeFries, J. C., Gottesman, I. I., Loehlin, J. C., Meyer, J. M., Pelias, J., Rice, J., and Waldman, I. (1997). 'Recent developments in human behavioral genetics: Past accomplishments and future directions', American Journal of Human Genetics, 60, 1265-75.

Siamwalla, A. (1978). 'Farmers and middlemen: Aspects of agricultural marketing in Thailand', Economic Bulletin for Asia and the Pacific, 39, $38-50$.

Simon, H. A. (1990). 'A mechanism for social selection and successful altruism', Science, 250, 1665-67.

Slonim, R. and Roth, A. E. (1998). 'Learning in high stakes ultimatum games: An experiment in the Slovak Republic', Econometrica, 66, $569 \ldots 96$.

Smith, N. (2001). Ethnicity, Reciprocity, Reputation and Punishment: An Ethnoexperimental Study Among the Chaldeans and Hmong of Detroit. Unpublished dissertation, University of California, Los Angeles.

Sober, E. and Wilson, D. S. (1994). 'Reintroducing group selection to the human behavioral sciences', Behavioral and Brain Sciences, 17, 585-654.

Tversky, A. and Kahneman, D. (1992). 'Advances in prospect theory: Cumulative representation of uncertainty', Journal of Risk and Uncertainty, 5, 297-323.

Woodburn, J. (1968). 'An introduction to the Hadza ecology', in R. B. Lee and I. De Vore (eds), Man the Hunter, Chicago, IL: Aldine, pp. 49-55.

\section{Measuring Social Norms and Preferences Using Experimental Games: A Guide for Social Scientists}

\author{
Colin F. Camerer and Ernst Fehr
}

\section{INTRODUCTION}

The purpose of this chapter is to describe a menu of experimental games that are useful for measuring aspects of social norms and social preferences. Economists use the term 'preferences' to refer to the choices people make, and particularly to tradeoffs between different collections ('bundles') of things they value - food, money, time, prestige, and so forth. 'Social preferences' refer to how people rank different allocations of material payoffs to themselves and others. We use the term 'self-interested' to refer to people who do not care about the outcomes of others. While self-interest can be a useful working assumption, experimental research of the $1980 \mathrm{~s}$ and 1990s have shown that a substantial fraction of people in developed countries (typically college students) also care about the payoffs of others. In some situations, many people are willing to spend resources to reduce the payoff of others. In other situations, the same people spend resources to increase the payoff of others.

As we will see, the willingness to reduce or increase the payoff of relevant reference actors exists even though people reap neither present nor future material rewards from reducing or increasing payoffs of others. This indicates that, in addition to self-interested behavior, people sometimes behave as if they have altruistic

This paper was prepared for the MacArthur Foundation Anthropology project meeting. This research was supported by NSF SBR9730364. Thanks to Sam Bowles, Jean Ensminger, and Joe Henrich for comments, and Natalie Smith for sharing figures from her paper. Ernst Fehr acknowledges support from the Swiss National Science Foundation (project number 1214-05100.97), the Network on the Evolution of Preferences and Social Norms of the MacArthur Foundation, and the EU-TMR Research Network ENDEAR (FMRX-CTP98-0238). Colin Camerer acknowledges support of the Preferences Network and NSF grant SES-0078911. 
preferences, and preferences for equality and reciprocity. ${ }^{1}$ Reciprocity, as we define it here, is different from the notion of reciprocal altruism in evolutionary biology. Reciprocity means that people are willing to reward friendly actions and to punish hostile actions although the reward or punishment causes a net reduction in the material payoff of those who reward or punish. Similarly, people who dislike inequality are willing to take costly actions to reduce inequality, although this may result in a net reduction of their material payoff. Reciprocal altruism typically assumes that reciprocation yields a net increase in the material payoff (e.g. because one player's action earns them a reputation which benefits them in the future). Altruism, as we define it here, means that an actor takes costly actions to increase the payoff of another actor, irrespective of the other actor's previous actions. Altruism thus represents unconditional kindness while reciprocity means non-selfish behavior that is conditioned on the previous actions of the other actor.

Reciprocity, inequality aversion, and altruism can have large effects on the regularities of social life and, in particular, on the enforcement of social norms. This is why the examination of the nature of social preferences is so important for anthropology and for social sciences in general. There is, for example, an ongoing debate in anthropology about the reasons for food-sharing in smallscale societies. The nature of social preferences will probably have a large effect on the social mechanism that sustains food-sharing. For example, if many people in a society exhibit inequality aversion or reciprocity, they will be willing to punish those who do not share food, so no formal mechanism is needed to govern food-sharing. Without such preferences, formal mechanisms are needed to sustain food-sharing (or sharing does not occur at all). As we will see there are simple games that allow researchers to find out whether there are norms of food-sharing, and punishment of those who do not share.

In the following we first sketch game theory in broad terms. Then we describe some basic features of experimental design in economics. Then we introduce a menu of seven games that have proved useful

${ }^{1}$ We defer the question of whether these preferences are a stable trait of people, or tend to depend on situations. While many social scientists tend to instinctively guess that these preferences are traits of people, much evidence suggests that cross-situational behavior is not very consistent at the individual level. Note, however, that behaviotal variations across situations do not imply that preferences vary across situations because individuals with fixed preferences may well behave differently in different situations (see section on 'Theories of Social Preferences'). in examining social preferences. We define the games formally, show what aspects of social life they express, and describe behavioral regularities from experimental studies. The behavioral regularities are then interpreted in terms of preferences for reciprocity, inequity aversion, or altruism. The final sections describe some other games anthropologists might find useful, and draw conclusions.

\section{GAMES AND GAME THEORY}

Game theory is a mathematical language for describing strategic interactions and their likely outcomes. A game is a set of strategies for each of several players, with precise rules for the order in which players choose strategies, the information they have when they choose, and how they rate the desirability ('utility') of resulting outcomes. Game theory is designed to be flexible enough to be used at many levels of detail in a broad range of sciences. Players may be genes, people, groups, firms, or nation-states. Strategies may be genetically coded instincts, heuristics for bidding on the e-Bay website, corporate routines for developing and introducing new products, a legal strategy in complex mass tort cases, or wartime battle plans. Outcomes can be anything players value-prestige, food, control of Congress, sexual opportunity, returning a tennis serve, corporate profits, the gap between what you would maximally pay for something and what you actually pay ('consumer surplus'), a sense of justice, or captured territory.

Game theory consists of two different enterprises: (1) using games as a language or taxonomy to parse the social world; and (2) deriving precise predictions about how players will play in a game by assuming that players maximize expected 'utility' (personal valuation) of consequences, plan ahead, and form beliefs about other players' likely actions. The second enterprise dominates game theory textbooks and journals. Analytical theory of this sort is extremely mathematical, and inaccessible to many social scientists outside of economics and theoretical biology. Fortunately, games can be used as a taxonomy with minimal mathematics because understanding prototypical games-like those discussed in this chapter- requires nothing beyond simple logic.

The most central concept in game theory is Nash equilibrium. A set of strategies (one for each player) form an equilibrium if each 
player is choosing the strategy which is a best response (i.e. gives the highest expected utility) to the other players' strategies. Attention is focused on equilibrium because players who are constantly switching to better strategies, given what others have done, will generally end up at an equilibrium. Increasingly, game theorists are interested in the dynamics of equilibration as well, in the form of evolution of populations of player strategies (Weibull 1995); or learning by individuals from experience (e.g. Fudenberg and Levine 1998; Camerer and Ho 1999).

\section{Conventions in economic experimentation}

At this point, it is useful to describe how experimental games are typically run (see Friedman and Sunder 1994; Davis and Holt 1993; Camerer 2003 for more methodological details). Experimental economists are usually interested initially in interactions among anonymous agents who play once, for real money, without communicating. This stark situation is not used because it is lifelike (it's not). It is used as a benchmark from which the effects of playing repeatedly, communicating, knowing who the other player is, and so forth, can be measured by comparison.

In most experiments described below, subjects are college undergraduates recruited from classes or public sign-up sheets (or increasingly, email lists, or websites) with a vague description of the experiment (e.g. 'an experiment on interactive decision-making') and a range of possible money earnings. The subjects assemble and are generally assigned to private cubicles or as groups to rooms. Care is taken to ensure that any particular subject will not know precisely whom they are playing. If subjects know with whom they are playing, their economic incentives may be distorted in a way the experimenter does not understand (e.g. they may help friends earn more) and there is an opportunity for postgame interaction which effectively changes the game from a one-shot interaction to a repeated interaction.

The games are usually described in plain, abstract language, using letters or numbers to represent strategies rather than concrete descriptions like 'helping to clean up the park' or 'trusting somebody in a faraway place'. As with other design features, abstract language is used not because it is lifelike, but as a benchmark against which the effects of more concrete descriptions can be measured. It is well-known that there are framing effects, or violations of the principle of description invariance-how the experiment is described may matter. For example, in Public Goods Games, players who are asked to take from a common pool for their private gain typically behave differently than subjects who are asked to give to the common pool by sacrificing (Andreoni 1995). Subjects generally are given thorough instructions, encouraged to ask questions, and are often given a short quiz to be sure they understand how their choices (combined with choices of others) will determine their money earnings. Economists are also obsessed with offering substantial financial incentives for good performance, and many experiments have been conducted which show that results generalize even when stakes are very large (on the order of several days' or even months' wages).

Since economists are typically interested in whether behavior corresponds to an equilibrium, games are usually played repeatedly to allow learning and equilibration to occur. Because playing repeatedly with the same player can create different equilibria, in most experiments subjects are rematched with a different subject each period in a 'stranger' protocol. (In the opposite, 'partner' protocol, a pair of subjects know they are playing each other repeatedly.) In a design called 'stationary replication', each game is precisely like the one before. This is sometimes called the 'Groundhog Day' design, after a movie starring Bill Murray in which Murray's character relives the same day over and over. (At first he is horrified, then he realizes he can learn by trial and error because the events of the day are repeated identically.)

After subjects make choices, they are usually given feedback on what the subject with whom they are paired has done (and sometimes feedback on what all subjects have done), and compute their earnings. Some experiments use the 'strategy method' in which players make a choice conditional on every possible realization of a random variable or choice by another player (e.g. in a bargaining game, subjects might be asked whether they would accept or reject every offer the other player could make. Their conditional decision is then enacted after the other player's offer is made). At the end of the experiment, subjects are paid their actual earnings plus a small show up' fee (usually US\$3-\$5). In experimental economics, there is a virtual taboo against deceiving subjects by actively lying about the experimental conditions, such as telling them they are playing 
another person when they are not (which is quite common in social psychology). A major reason for this taboo is that, for successful experimentation, subjects have to believe the information that is given to them by the experimenter. In the long run deception can undermine the credibility of the information given to the subjects.

The seven examples wc will discuss are Prisoner's Dilemma. public goods, ultimatum, dictator, trust, gift exchange, and thirdparty punishment games. Table 3.1 summarizes the definitions of the games (and naturally occurring examples of them), the predictions of game theory (assuming self-interest and rational play). experimental regularities, and the psychological interpretation of the evidence.

\section{Prisoners' dilemma and public goods games}

Figure 3.1 shows payoffs in a typical Prisoner's Dilemma. The rows and columns represent simultaneous choices by two players. Each cell shows the payoffs from a combination of row and column player moves; the first entry is the row player's payoff and the second entry is the column players payoff. For example, $(T, S)$ in the (Defect, Cooperate) cell means a defecting row player earns $T$ when the column player cooperates, and the column player earns $S$

Mutual cooperation provides payoffs of $\mathrm{H}$ for each player, which is--by definition of a Prisoner's Dilemma - better than the $L$ payoff from mutual defection. However, if the other player plays $\mathrm{C}$, a defector earns the $T$ (emptation) payoff $\mathrm{T}$, which is better than reciprocating and earning only $\mathrm{H}$ (since $\mathrm{T}>\mathrm{H}$ in a Prisoner's Dilemma). A player who cooperates against a defector earns the $S$ (ucker) payoff, which is less than earning $L$ from defecting. Since $\mathrm{T}>\mathrm{H}$ and $\mathrm{L}>\mathrm{S}$, both players prefer to defect whether the other player cooperates or not. So mutual defection is the only Nash (mutual best-response) equilibrium. ${ }^{2}$ This equilibrium is

${ }^{2}$ It is important to note the distinction between outcomes that are measured $i_{n}$ field data or paid in experiments, and the utilities or personal valuations attached to those rewards. Game theory allows the possibility that players get utility from sometning other than their own rewards (e.g. they may feel pride or envy if others earn lots of money). In practice, however, we observe only the payoffs players earn. For the purpose of this chapter, when we assume 'self-interest' we mean that players are solely motwater to maximize their own measured earnings in dollars (or food, or some other obserted outcome).

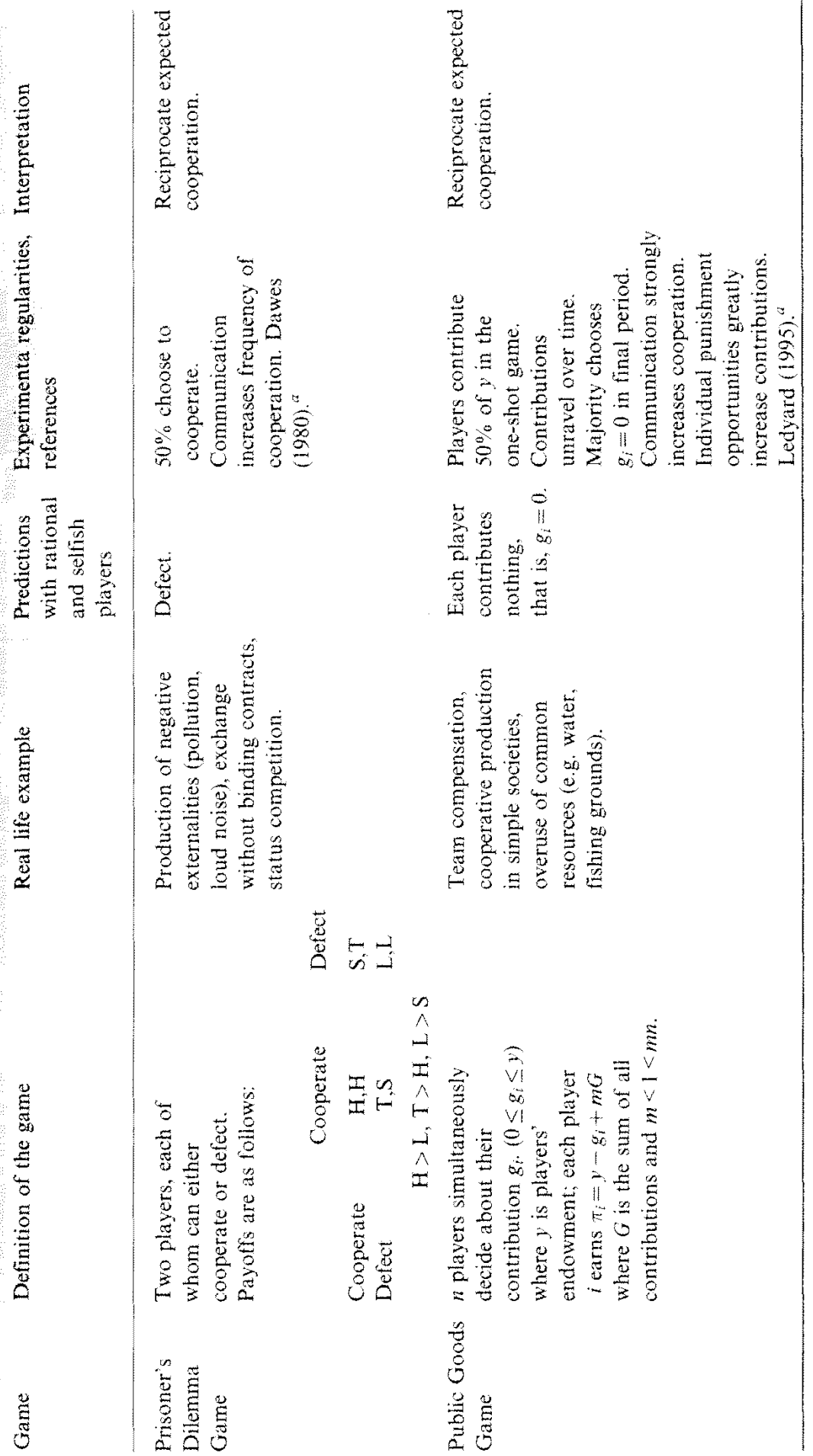


TABLE 3.1. Continued

\begin{tabular}{|c|c|c|c|c|c|}
\hline Game & $\begin{array}{l}\text { Definition } \\
\text { of the game }\end{array}$ & $\begin{array}{l}\text { Real life } \\
\text { example }\end{array}$ & $\begin{array}{l}\text { Predictions } \\
\text { with rational } \\
\text { and selfish } \\
\text { players }\end{array}$ & $\begin{array}{l}\text { Experimenta } \\
\text { regularities, } \\
\text { references }\end{array}$ & Interpretation \\
\hline $\begin{array}{l}\text { Ultimatum } \\
\text { Game }\end{array}$ & $\begin{array}{l}\text { Division of a fixed sum } \\
\text { of money } S \text { between a } \\
\text { proposer and a responder. } \\
\text { proposer offers } x \text {. If } \\
\text { responder rejects } x \\
\text { both earn zero, if } \\
x \text { is accepted the } \\
\text { proposer earns } S-x \text { and } \\
\text { the responder earns } x \text {. }\end{array}$ & $\begin{array}{l}\text { Monopoly pricing of a } \\
\text { perishable good; "llth } \\
\text { hour' settlement offers } \\
\text { before a time deadline. }\end{array}$ & $\begin{array}{l}\text { Offer } x=\varepsilon \text { where } \\
\varepsilon \text { is the smallest } \\
\text { money unit. } \\
\text { Any } x>0 \text { is } \\
\text { accepted. }\end{array}$ & $\begin{array}{l}\text { Most offers are } \\
\text { between } 0.3 \text { and } 0.5 S . \\
x<0.2 S \text { rejected } \\
\text { half the time. } \\
\text { Competition among } \\
\text { proposers has a } \\
\text { strong } x \text {-increasing } \\
\text { effect; competition } \\
\text { among responders } \\
\text { strongly decreases } x \text {. } \\
\text { Guth, Schmitterbert and } \\
\text { Schwartze }(1982),{ }^{b} \\
\text { Camerer }(2003) .\end{array}$ & $\begin{array}{l}\text { Responders punish } \\
\text { unfair offers; } \\
\text { negative reciprocity. }\end{array}$ \\
\hline
\end{tabular}

$\begin{array}{lll}\begin{array}{l}\text { Dictator } \\ \text { Game }\end{array} & \begin{array}{l}\text { Like the UG but the } \\ \text { responder cannot } \\ \text { reject, that is, the 'proposer' } \\ \text { dictates }(S-x, x) .\end{array} & \begin{array}{l}\text { Charitable sharing of a } \\ \text { windfall gain (lottery } \\ \text { winners giving } \\ \text { anonymously } \\ \text { to strangers). }\end{array}\end{array}$

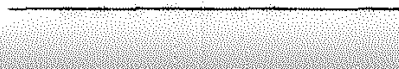

\section{Trust}

Game
Investor has endowment $S$ and makes a transfer $y$ between 0 and $S$ to the trustee. Trustee receives $3 y$ and can send back any $x$ between 0 and $3 y$. Investor earns $S-y+x$. Trustee earns $3 y-x$.

\begin{tabular}{|c|c|c|c|c|c|}
\hline $\begin{array}{l}\text { Gift } \\
\text { Exchange } \\
\text { Game }\end{array}$ & $\begin{array}{l}\text { 'Employer' offers a wage } \\
w \text { to the 'Worker' } \\
\text { and announces a desired } \\
\text { effort level } \hat{e} \text {. If worker } \\
\text { rejects ( } w \text {, } e \text { both earn } \\
\text { nothing. If Worker } \\
\text { accepts, he can choose } \\
\text { any } e \text { between } 1 \text { and } 10 \text {. } \\
\text { Then Employer earns } \\
10 e-w \text { and Worker } \\
\text { earn } w-c(e) \text {. c } e \text { ) is the } \\
\text { effort cost which is strictly' } \\
\text { increasing in } e \text {. }\end{array}$ & $\begin{array}{l}\text { Noncontractibility or } \\
\text { nonenforceability of } \\
\text { the performance } \\
\text { (effort, quality of } \\
\text { goods) of workers } \\
\text { or sellers. }\end{array}$ & $\begin{array}{l}\text { Worker chooses } \\
e=1 . \text { Employer pays } \\
\text { the minimum wage. }\end{array}$ & $\begin{array}{l}\text { Effort increases with } \\
\text { the wage } w \text {. Employers } \\
\text { pay wages that are far } \\
\text { above the minimum. } \\
\text { Workers accept offers } \\
\text { with low wages but } \\
\text { respond with } e=1 \text {. In } \\
\text { contrast to the UG } \\
\text { competition among } \\
\text { workers (i.e. responders) } \\
\text { has no impact on wage } \\
\text { offers. Fehr, Kirchsteiger, } \\
\text { and Riedl (1993). }\end{array}$ & $\begin{array}{l}\text { Workers reciprocate } \\
\text { generous wage } \\
\text { offers. Employers } \\
\text { appeal to } \\
\text { workers reciprocity } \\
\text { by offering } \\
\text { generous wages. }\end{array}$ \\
\hline $\begin{array}{l}\text { Third-Party } \\
\text { Punishment } \\
\text { Game }\end{array}$ & $\begin{array}{l}\text { A and B play a DG. } \\
C \text { observes } \\
\text { how much } \\
\text { of amount } S \text { is } \\
\text { allocated to } B \text {. } \\
C \text { can punish } \\
\text { A but the punishment } \\
\text { is also costly for } C \text {. }\end{array}$ & $\begin{array}{l}\text { Social disapproval of } \\
\text { unacceptable treatment } \\
\text { of others (scolding } \\
\text { neighbors). }\end{array}$ & $\begin{array}{l}\text { A allocates nothing } \\
\text { to } \mathrm{B} \text {. C never } \\
\text { punishes } \mathrm{A} \text {. }\end{array}$ & $\begin{array}{l}\text { Punishment of } \mathrm{A} \text { is } \\
\text { higher, the less } \mathrm{A} \\
\text { allocates to } \mathrm{B} \text {. } \\
\text { Fehr and Fischbacher } \\
(2001 a)^{b}\end{array}$ & $\begin{array}{l}\text { C sanctions } \\
\text { violation of a } \\
\text { sharing norm. }\end{array}$ \\
\hline
\end{tabular}

Note: ${ }^{a}$ Denotes survey papers. ${ }^{b}$ denotes papers that introduced the respective games.

Sequential exchange without binding contracts (buying from sellers on e-Bay).
Trustee repays nothing: $x=0$. Investor invests nothing: $y=0$.
On average $y=0.5 S$ and trustees repay slightly less than $0.55 . x$ is increasing in $y$. Berg Dickhaut, and McCabe (1995), Camerer $(2003){ }^{a}$
Trustees show positive reciprocity.

$995) ?^{b}$




$\begin{array}{lcc} & \text { Cooperate (C) } & \text { Defect (D) } \\ \text { Cooperate (C) } & \text { H, H } & \text { S, T } \\ \text { Defect (D) } & \text { T, S } & \text { L, L }\end{array}$

FIG. 3.1. Prisoner's Dilemma

Note: (Assumption: $\mathrm{T}>\mathrm{H}>\mathrm{L}>\mathrm{S}$ ). inefficient because mutual cooperation would render both
players better off.

Public goods games have an incentive structure similar to Prisoner's Dilemma games. ${ }^{3}$ Every player is best off by contributing nothing to the public good, but contributions from everyone would
make everyone better off.

The following experiment illustrates a typical Public Goods Game. There are $n$ subjects in a group and each player has an endowment of $y$ dollars. Each player can contribute between zero to the group project, project. For each dollar that is contributed controup member (including those who sures the marginal private $m<1$ dollars. The return $m$ thus meaproject (i.e the amount of return from a contribution to the group project (i.e. the amount of her investment which a specific individual gets back, in the form of her share of the public good). Since a subject benefits from the contributions of the others it is possible to condition $m n>1$. The pridributions. The parameter $m$ also obeys the the whole group fo product $m n$ is the total marginal return for the whole group from a contribution of one more dollar. For each dollar that is kept by a subject, that subject earns exactly one dollar. The total material payoff $\pi$ of a subject that contributes $g$ dollars is therefore, given by $\pi=y-g+m G$ where $G$ is the sum of the contributions of all $n$ group members. ${ }^{5}$ Self-interested subjects should contribute nothing to the public good, regardless of how much the

3 There is a huge literature on Public Goods Games. For a survey see Ledyard (1995).
${ }^{4}$ In the general case players in the Public Goods Game heve an tribute inefficiently little to the good. In most Goods Game have an incentive to conincentive to contribute nothing.

In the general case players may have unequal endowments $y_{i}$ and they may derive
unequal benefits $m_{i}$ from the public material payoff of player $i$ can then good $G \cdot m_{i}$ may also depend nonlinearly on $G$. The anthropology experiments it is adviable bressed as $\pi_{i}=y_{i}-g_{i}+m_{i}(G) G$. However, for possible to prevent that subjects are confused the experimenter doubles the $n>2$ group members. other subjects contribute. Why? Because every dollar spent on the group project costs the subject one dollar but yields only a private ferturn of $m<1$. This means that, in equilibrium, all self-interested subiects will contribute nothing to the public good. A group of selfinterested subjects earns $y$ dollars in this experiment because $G=0$. But since the total return for the group $m n$ is larger than one, the Goup as a whole benefits from contributions. If all group members invest their entire endowments $\mathrm{y}$, then $G=n y$ which means each subject earns $m n y$ rather than $y$ (which is better because $m n$ is larger than one). Thus, contributing everything to the group project renders all subjects better off relative to the equilibrium of zero contributions, but an individual subject does even - better by contributing nothing.

The Prisoner's Dilemma and Public Goods Games are models of situations like pollution of the environment, in which one player's action imposes a harmful 'externality' on innocent parties (cooperation corresponds to voluntarily limiting pollution), villagers sharing a depletable resource like river water or fish in a common fishing ground with poor enforcement of property rights (e.g. Ostrom 2000), and production of a public utility like a school or irrigation system that noncontributing 'free riders' cannot be easily excluded from sharing. Note also that contributions in public goods games are often in the form of time rather than money--for example, helping to clean up a public park or standing watch for village security. Low rates of voluntary cooperation and contribution in these games might be remedied by institutional arrangements like government taxation (which forces free riders to pay up), or informal mechanisms like ostracism of free riders. (Of course, if ostracism is costly then players should free ride on the ostracism supplied by others, which creates a second-order public good problem.) Also, when Prisoner's Dilemma and Public Goods Games involve players who are matched together repeatedly, it can be an equilibrium for players to all cooperate until one player defects. Sometimes the experimenter wants to allow for stationary replication but, at the same time, wants to prevent the existence of equilibria that involve positive contribution levels. This can be achieved by changing the group composition from period to period such that no player ever meets another player more than once.

In the Prisoner's Dilemma, self-interested subjects have an incentive to defect. In the Public Goods Game, when $m<1$, the 
self-interest hypothesis predicts zero contributions. In experiments, however, subjects in one-period Prisoner's Dilemma games cooperate about half of the time. In one-period Public Goods Games, they contribute an average of a half of their endowment, but the distribution is typically bimodal with most subjects contributing either everything or nothing. Higher values of the private return $m$ lead to higher contributions. Similar effects are obtained in the Prisoner's Dilemma. An increase in the value of $H$, relative to $T$, increases the rate of cooperation. Interestingly, pre-play communication about how much players intend to contribute, which should have no effect in theory, has a very strong positive impact on cooperation levels in both the Prisoner's Dilemma and Public Goods Games (Ledyard 1995; Sally 1995).

When the Public Goods Game is repeated for a finite number of periods, interesting dynamic contribution patterns emerge. Irrespective of whether subjects can stay together in the same group or whether the group composition changes from period to period, subjects initially contribute as much as they do in one-period games, but contributions decline substantially over time. Approximately $60-80$ percent of all subjects contribute nothing in the final period and the rest contribute little. ${ }^{6}$ The first ten periods of Figure 3.2 show the dynamic pattern of average contributions in a standard Public Goods Game like the one described above. Another important fact is that about half the subjects are 'conditional cooperators'- - they contribute more when others are expected to contribute more and do contribute more (Croson 1999; Fischbacher, Gächter, and Fehr 2001). Conditional cooperation is not compatible with pure self-interest, but consistent with a preference for behaving reciprocally. The studies cited above also indicate that

${ }^{6}$ Initially, many experimentalists interpreted this as a victory of the self-interest hypothesis (Isaac, McCue, and Plott 1985). It was thought that at the beginning of the experiment subjects do not yet fully understand what they rationally should do (even though the incentive to free ride is usually transparent and is often pointed out very explicitly in the instructions) but over time they learn what to do and in the final period the vast majority of subjects behave self-interestedly. This interpretation is wrong. Andreoni (1988) showed that if one conducts a 'surprise' second Public Goods Game after the final period of a first game, subjects start the new game with high contribution levels (similar to initial levels in the first game). If players had learned to free ride over time, this 'restart' effect would not occur; so the dynamic path that is observed is more likely to be due to learning by conditional cooperators about the presence and behavior of free riders, rather than simply learning that free riding is more profitable. Camerer and Weigelt (1988) observed the same kind of restart effect in repeated trust games.

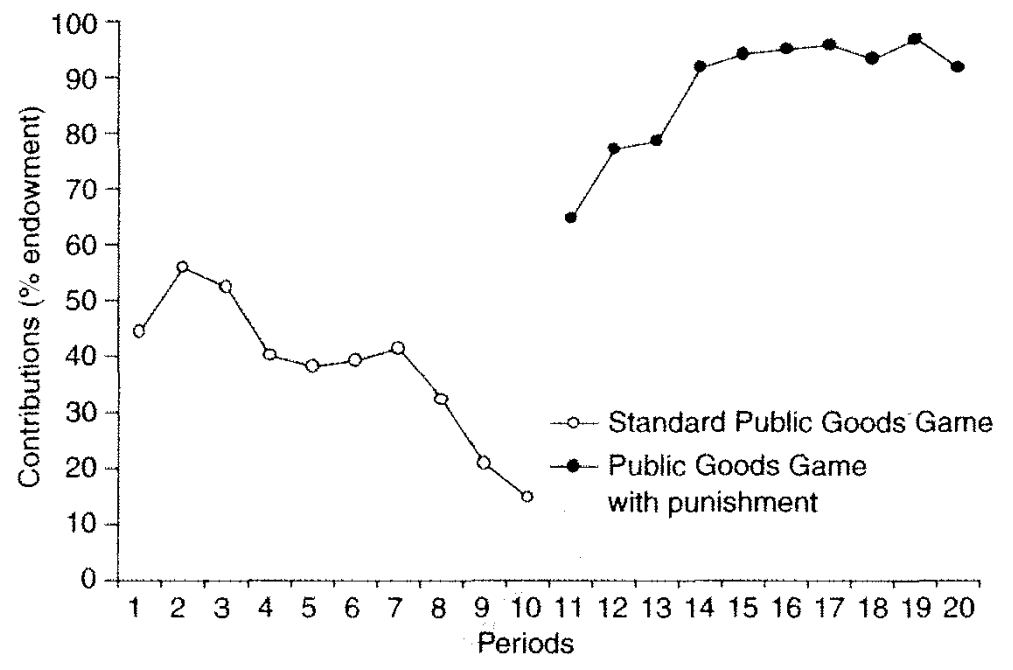

Frg. 3.2. Average contributions over time in Public Goods Game with a constant group composition

Source: Fehr and Gächter $(2000)$.

about a third of the subjects are purely self-interested, and never contribute anything.

Why do average contributions decline over time? A plausible explanation is that each group has a mixture of subjects who behave selfishly and others who behave reciprocally. The reciprocal subjects are willing to cooperate if the other group members cooperate as well. However, in the presence of selfish subjects who never contribute, reciprocal subjects gradually notice that they are matched with free riders and refuse to be taken advantage of by them.

The unraveling of cooperation over time raises the question of whether there are social mechanisms that can prevent the decay of cooperation. A potentially important mechanism is social ostracism. In a series of experiments, Fehr and Gächter (2000) introduced a punishment opportunity into the Public Goods Game

7 The existence of conditional cooperators may also explain framing effects in public goods and Prisoner's Dilemma games (see Ross and Ward (1996)). If, for example, a Prisoner's Dilemma game is described as the 'Wall Street' game, subjects are likely to have pessimistic expectations about the other players' cooperation. Conditional cooperators are, therefore, likely to defect in this frame. If, in contrast, the Prisoner's Dilemma is described as a 'Community' game, subjects probably have more optimistic expectations about the cooperation of the other player. Hence, the conditional cooperators are more likely to cooperate in this frame. 
(see also Yamagishi 1966). In their game there are two stages. Stage one is a Public Goods Game as described above. In stage two, after every player in the group has been informed about the contributions of each group member, each player can assign up to ten punishment points to each of the other players. The assignment of one punishment point reduces the first-stage income of the punished subject by 10 percent but it also reduces the income of the punisher. (The punishment is like an angry group member scolding a free rider, or spreading the word so the free rider is ostracized there is some cost to the punisher, but a larger cost to the free rider.) Note that since punishment is costly for the punisher, the self-interest hypothesis predicts zero punishment. Moreover, since rational players will anticipate this, the self-interest hypothesis predicts no difference in the contribution behavior between the standard Public Goods Game and the game with a punishment opportunity. In both conditions zero contributions are predicted.

The experimental evidence rejects this prediction. ${ }^{8}$ In contrast to the standard Public Goods Game, where cooperation declines over time and is close to zero in the final period (see the first ten periods in Figure 3.2), the punishment opportunity causes a sharp jump in cooperation (compare period 10 with period 11 in Figure 3.2) and a steady increase until almost all subjects contribute their whole endowment. The sharp increase occurs because free riders often get punished, and the less they give, the more likely punishment is. Cooperators feel that free riders take unfair advantage of them and, as a consequence, they are willing to punish the free riders. This induces the punished free riders to increase cooperation in the following periods. A nice feature of this design is that the actual rate of punishment is very low in the last few periods - the mere threat of punishment, and the memory of its sting from past punishments, is enough to induce potential free riders to cooperate.

The results in Figure 3.2 are based on a design in which the same group of players are paired together repeatedly (the 'partner' protocol). When the group composition changes randomly from period to period or when subjects are never matched with the same group members again (the 'stranger' protocol), cooperation levels are lower than in the partner design, but the dynamic pattern is similar

${ }^{8}$ In the experiments subjects first participated in the standard game for ten periods. After this they were told that a new experiment takes place. In the new experiment which lasted again ten periods, the punishment opportunity was implemented. to Figure 3.2. Interestingly, the punishment pattern is almost the same in the partner and the stranger protocol. This means that, in the partner protocol, the strategic motive of inducing future cooperation is not an important cause of the punishment.

The Public Goods Game with a punishment opportunity can be viewed as the paradigmatic example for the enforcement of a social norm. Social norms often demand that people give up private benefits to achieve some other goal. This raises the question of why most people obey the norm. The evidence above suggests an answer: some players will punish those who do not obey the norm (at a cost to themselves), which enforces the norm.

Another mechanism that causes strong increases in cooperation is communication (Sally 1995). If the group members can communicate with each other, the unraveling of cooperation frequently does not occur. Communication allows the conditional cooperators to coordinate on the cooperative outcome and it may also create a sense of group identity.

While Prisoner's Dilemma and Public Goods Games capture important components of social life, they cannot typically distinguish between players who are self-interested, and players who would like to reciprocate but believe pessimistically that others will not cooperate or contribute. Other games are useful for separating out these different types of players. Three other games have proved useful in separating these two explanations and measuring a wider range of social preferences--ultimatum, dictator, and trust games.

\section{Ultimatum Games}

Ultimatum Games represent a form of take-it or leave-it bargaining (Güth, Schmittberger, and Schwarze 1982). One player, a proposer, can make only one proposal regarding the division of a fixed amount of money $S$ between herself and a responder. The responder can accept the offer $x$, or reject it, in which case neither player earns anything. If the responder accepts, he earns $x$ and the proposer earns $S-x$. In theory, self-interested responders will accept any positive offer, and proposers who anticipate this should offer the smallest possible positive amount (denoted by $\varepsilon$ in Table 3.1).

The Ultimatum Game measures whether responders will negatively reciprocate, sacrificing their own money to punish a proposer who has been unfair. In dozens of experiments under different 


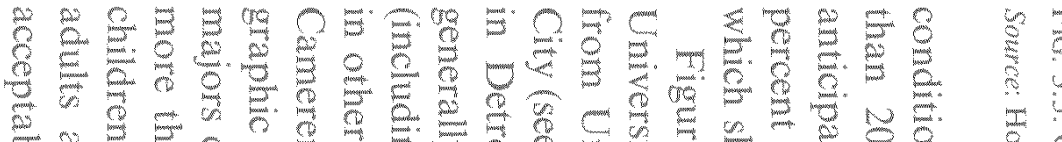

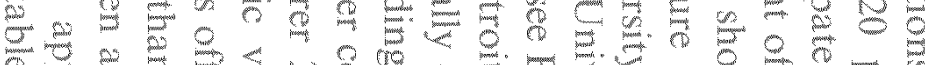

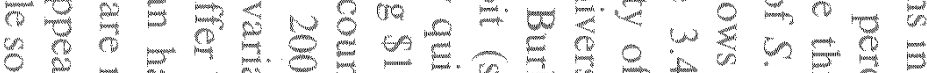

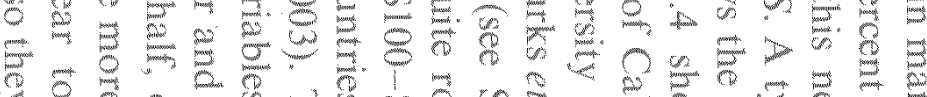

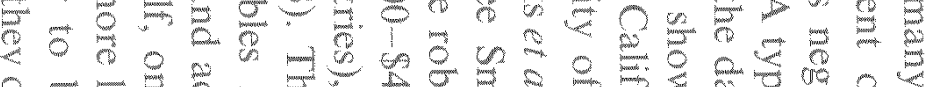

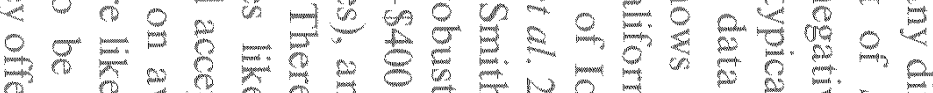

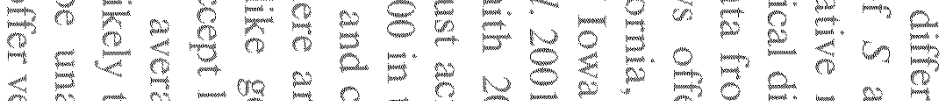

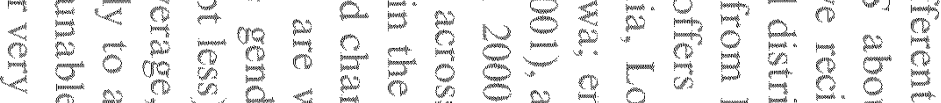

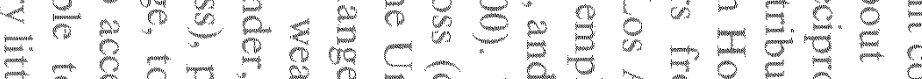

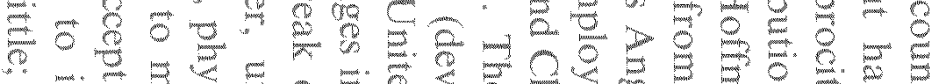

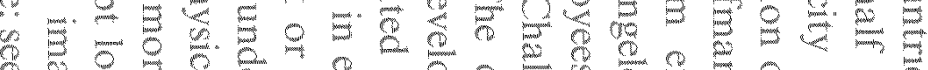
을

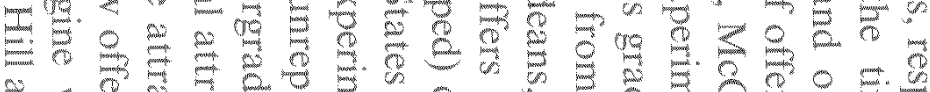

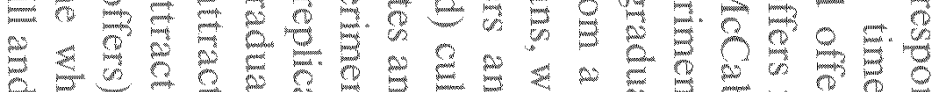

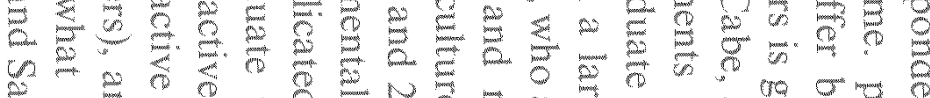

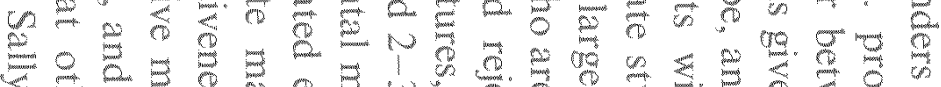

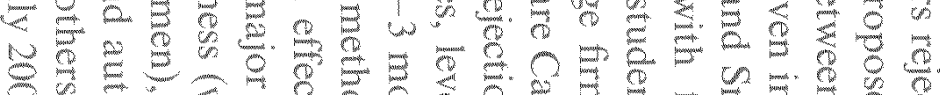

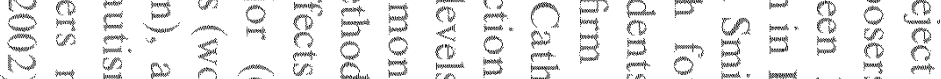

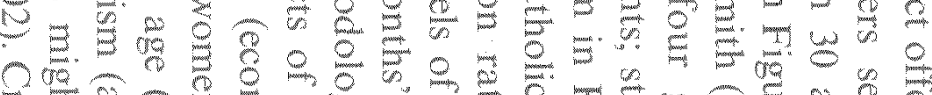

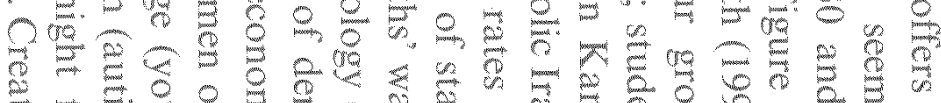
Frequency

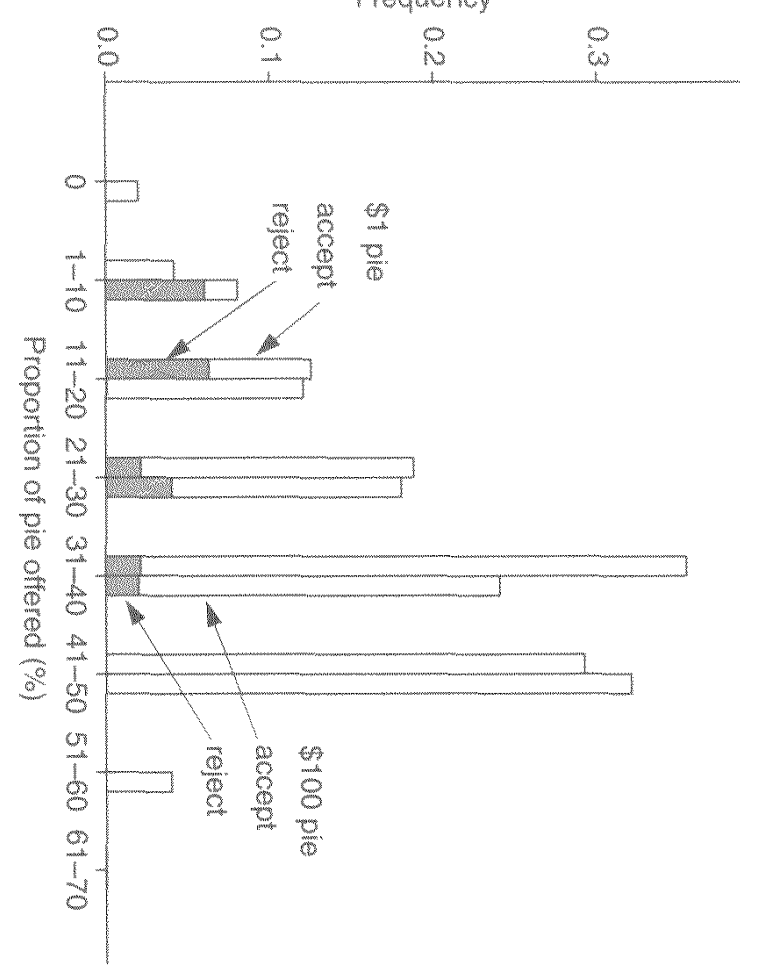

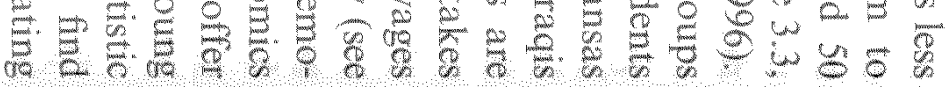

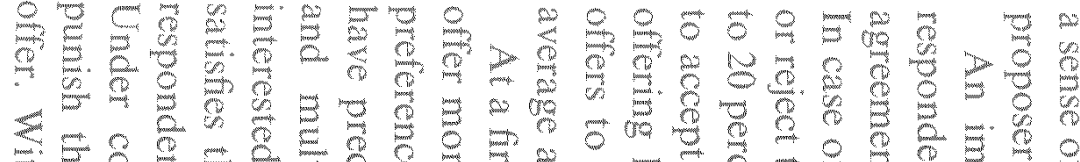

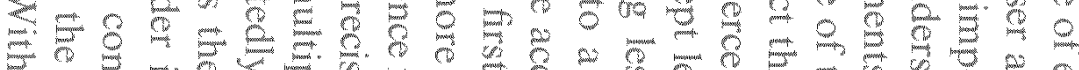

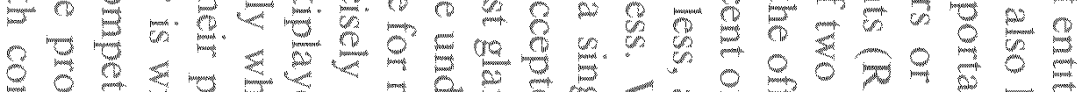

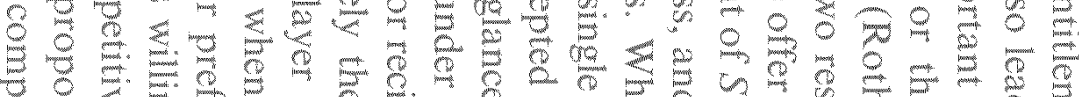

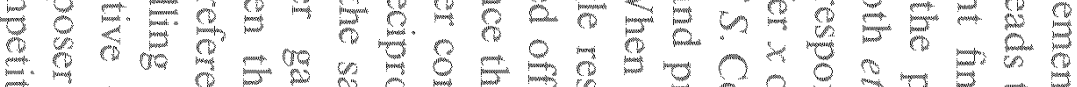

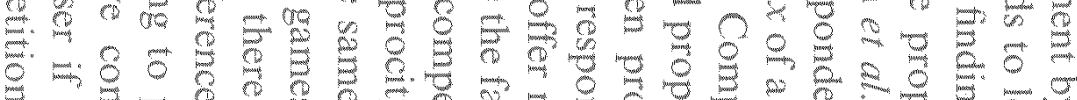

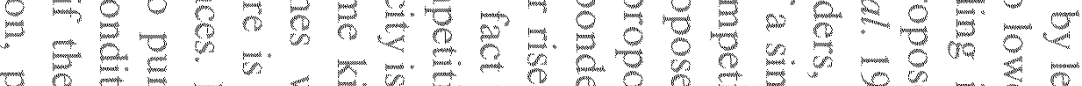

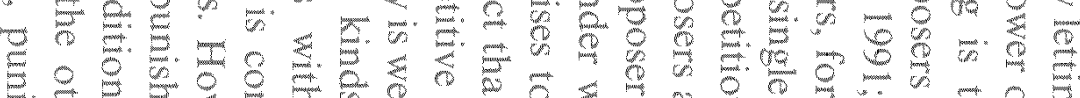

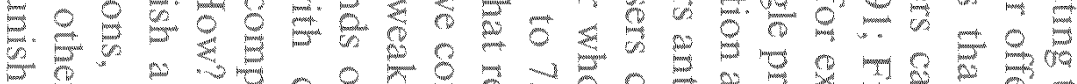

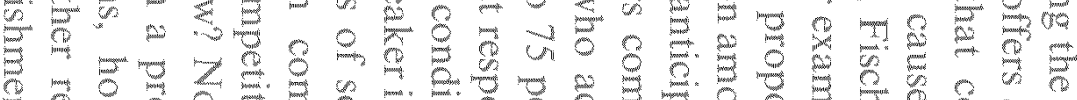

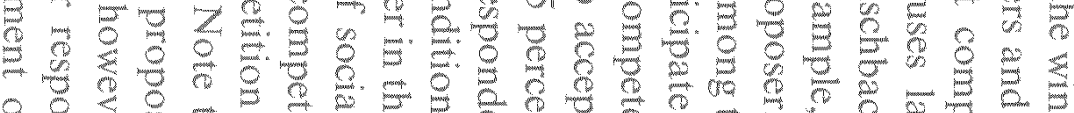

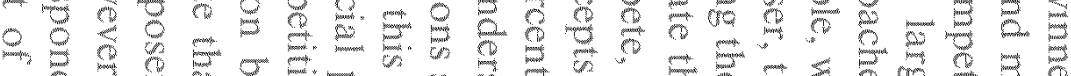

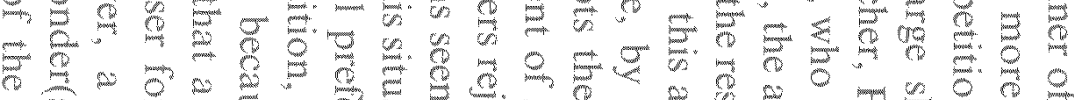

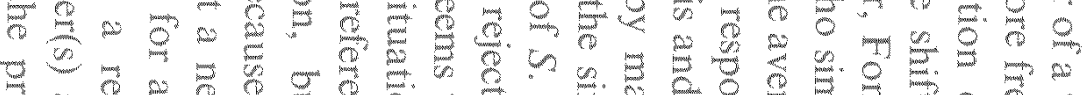

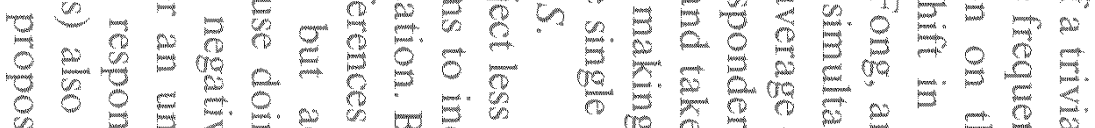

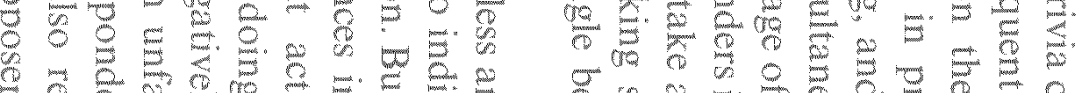
돈.

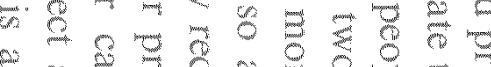

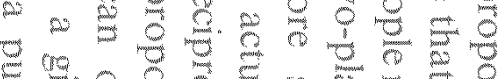

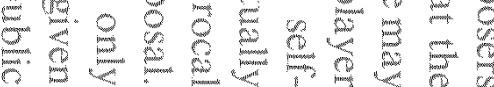

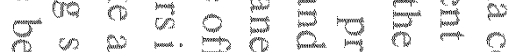

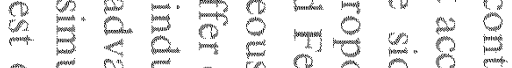
을

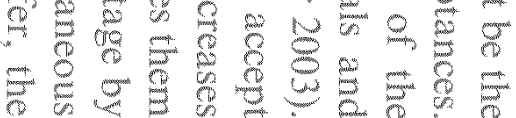

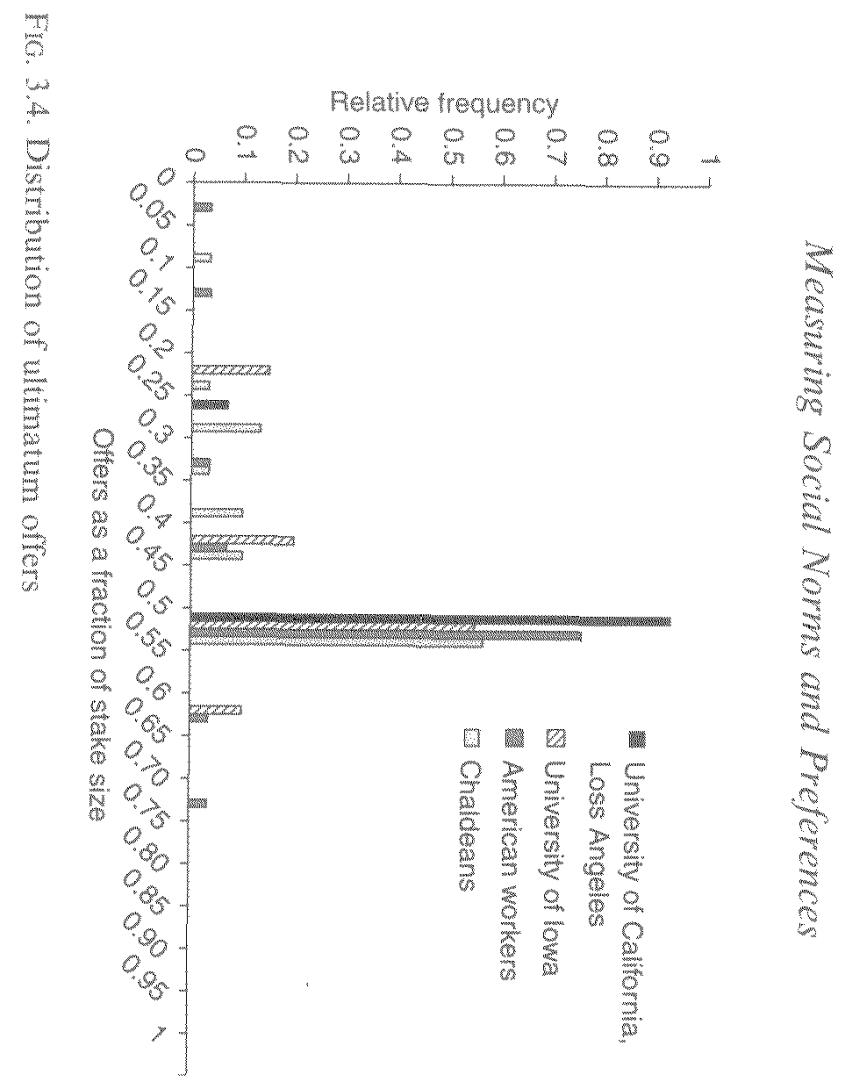

$\pm$ 
good that is only produced if all responders reject. Since there is always a positive probability to be matched with a self-interested responder, who accepts every positive offer, the reciprocal responder's rejection becomes futile. Hence, there is less advantage to rejecting under competition, even if one has a strong preference for reciprocity. Competition essentially makes it impossible for players to express their concern about reciprocity. Consequently, evidence of the self-interested behavior in the face of competition does not cast doubt on evidence of reciprocity in other domains.

The fact that proposers offer on average 40 percent of $S$ might be due to altruism, a preference for sharing equally, or to a fear that low offers will be rejected ('strategic fairness'). Although rejection rates are lower under competitive conditions there is still a significant rate of rejection. Thus, even under competitive conditions proposers have reason to fear that very low offers are rejected. Dictator games help separate the fear-of-rejection hypothesis from the other explanations mentioned above because the responder's ability to reject the offers is removed.

\section{Dictator Games}

A Dictator Game is simply a proposer division of the sum $S$ between herself and another player, the recipient (Kahneman, Knetsch, and Thaler 1986; Forsythe et al. 1994). Self-interested proposers should allocate nothing to the recipient in the Dictator Game. In experiments with students, proposers typically dictate allocations that assign the recipient on average between 10 and 25 percent of $S$, with modal allocations distributed between 50 percent and zero (see Figure 3.5, from Smith 2000). These allocations are much less than student proposers offer in Ultimatum Games, though most players do offer something. Comparing dictator with bilateral Ultimatum Games shows that fear of rejection is part of the explanation for proposers' generous offers, because they do offer less when there can be no rejection. But many subjects offer something in the Dictator Game, so fear of rejection is not the entire explanation. Moreover, the Chaldeans and the employees from Kansas City offer roughly the same in the Ultimatum Game and the Dictator Game."

${ }^{9}$ Unfortunately, there are so far not many experiments with non-student popula tions. It is therefore not clear to what extent the results from the Chaldeans (Smit: 2000) and from the Kansas City workers (Burks et al. 2001) represent general patterns in non-student populations.

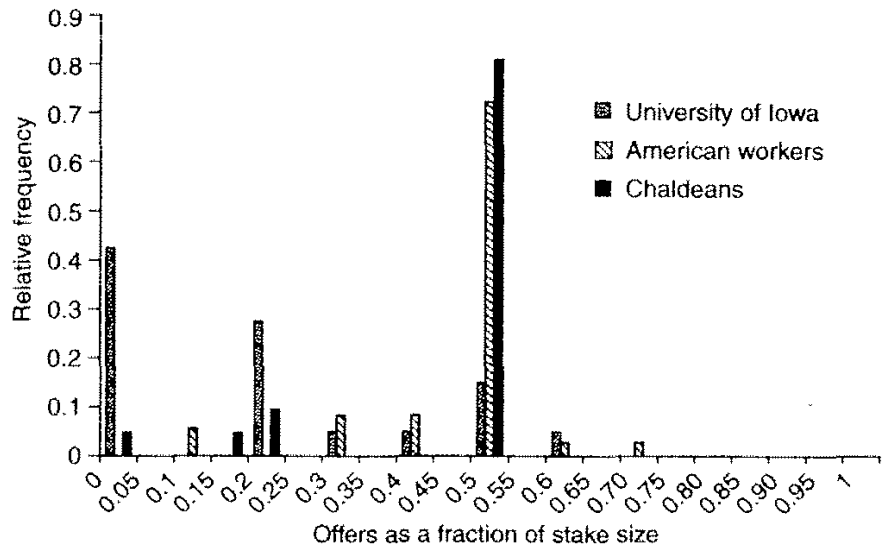

FIG. 3.5. Dictator Game allocations

The Dictator Game is a 'weak situation' because there is typically no strong norm for a reasonable allocation, so average allocations can change dramatically with changes in the experimental design. At one extreme, when experimenters take pains to ensure to subjects that their individual decisions cannot be identified by the experimenter (in 'double-blind' experiments), self-interest emerges more strongly (among students): About 70 percent of the proposers allocate nothing and the rest typically allocate only $10-20$ percent of $S$ (Hoffman et al. 1994). At the opposite extreme, when the eventual recipient of the proposer's allocation gives a short description of him or herself which the proposer hears, the average allocation rises to half of $S$, and allocations become more variable (Bohnet and Frey 1999). Many proposers give nothing and others give the entire amount, as if proposers make an empathetic judgment about the recipient's deservingness. These two extremes simply illustrate that dictator allocations can be strongly influenced by many variables (in contrast to ultimatum offers, which do not deviate too far from $30-50$ percent in most previous experiments with students).

Trust and gift exchange games

Dictator games measure pure altruism. An interesting companion game is the 'trust game' (see also Camerer and Weigelt 1988 and Berg, Dickhaut, and McCabe 1995). In a trust game an investor and trustee each receive an amount of money $S$ from the experimenter. 
The investor can invest all or part of her money by sending any amount $y$, between zero and $S$, to the trustee. The experimenter then triples the amount sent, so that the trustee has $3 y$ (in addition to her initial allocation of $S$ which is hers to keep). The trustee is then free to return anything between zero and $3 y$ to the investor The payoff of the investor is $S-y+z$ and the payoff of the trustee is $3 y-z+S$ where $z$ denotes the final transfer from the trustee to the investor. For example, suppose $S$ is $\$ 10$ and the investor invests $\$ 7$, keeping $\$ 3$. The $\$ 7$ investment triples to $\$ 21$. If the trustee repays $\$ 10$ and keeps $\$ 11$ for herself, then the investor gets a total of $\$ 3+\$ 10$, or $\$ 13$, and the trustee gets $\$ 10+\$ 11$, or $\$ 21$. Note that if investors do not invest, then together the two players earn $2 S$. If the investor invests everything, the players earn $4 S$ (the trustee's $S$ plus the tripled investment of $3 S$ ); so there is a large mutual gain from trust. The trust game is essentially a Dictator Game in which the trustee dictates an allocation, but the amount to be allocated was created by the investor's initial investment.

In theory, self-interested trustees will keep everything and repay $z=0$. Self-interested investors who anticipate this should transfer nothing, that is, $y=0$. In experiments in several developed countries, investors typically invest about half the maximum on average, although there is substantial variation across subjects. Trustees tend to repay slightly less than $y$ so that trust does not quite pay. The amount trustees repay increases with $y$, which can be interpreted as positive reciprocity, or a feeling of obligation to repay more to an investor who has exhibited trust.

Positive reciprocity like the one that shows up in the trust game has important implications for the enforcement of informal agreements and incomplete contracts. Most social relations are not governed by explicit contracts but by implicit informal agreements. Moreover. when explicit contracts exist they are often highly incomplete, which gives rise to strong incentives to shirk (Williamson 1985). Economic historians like North (1990) have argued that differences in societies contract enforcement capabilities are probably a major reason for differences in economic growth and human welfare, and Knack and Keefer (1997) find that countries with high measured trust (from surveys) have higher economic growth.

To see the role of reciprocity in the enforcement of contracts. consider the following variant of the gift exchange game (Fehr. Kirchsteiger, and Riedl 1993). In the gift exchange game subjects are in the role of employers or buyers and of workers or sellers, respectively. ${ }^{10}$ An employer can offer a wage contract that stipulates a binding wage $w$ and a desired effort level $\hat{e}$. If the worker accepted this offer, the worker is free to choose the actual effort level $e$ between a minimum and a maximum level. The employer always has to pay the offered wage irrespective of the actual effort level. In this experiment effort is represented by a number $e$ between one and ten. Migher numbers represent higher effort levels and, hence, a higher profit $\pi$ for the employer and higher effort $\operatorname{costs} c(e)$ for the worker. Thus, the lowest effort level gives the worker the highest material payoff but the highest material payoff for the employer is given at the maximal effort level. Formally, the profit $\pi$ from the employment of a worker is given by $\pi=10 \times e-w$ and the monetary payoff for the experimental worker is $u=w-c(e)$. The crucial point in this experiment is that selfish workers have no incentives to provide effort above the minimum level of $e=1$ irrespective of the level of wages. Employers who anticipate this behavior will, therefore, offer the smallest possible wage such that the worker just accept the contract offer. Reciprocal workers will, however, honor at least partly generous wage offers with non-minimal, generous, effort choices. The question, therefore, is to what extent employers do appeal to workers' reciprocity by offering generous contracts and to what extent workers honor this generosity.

It turns out that in experiments like this many employers indeed make quite generous offers. On average, the offered contracts stipulate a desired effort of $\hat{e}=7$ and the offered wage implies that the worker receives 44 percent of the total income that is generated if the worker indeed performs at $e=7$. Interestingly, a relative majority of the workers honor this generosity. Most of them do not fully meet the desired effort level but they choose levels above $e=1$. A minority of the workers (about 30 percent) always choose always the minimal effort. The average effort is $e=4.4$ substantially above the selfish choice of $e=1$. Moreover, there is also a strong positive correlation between effort and wages, indicating positive reciprocity. A typical effort-wage relation is depicted in Figure 3.6. Thus, although shirking exists in this situation the evidence suggests that in response to generous offers, a relative majority of the people

${ }^{10}$ In the following we stick to the employer-worker framing although the experiment could also be presented in a buyer-seller frame. The gift-exchange experiment has been conducted in both frames with virtually the same results. 


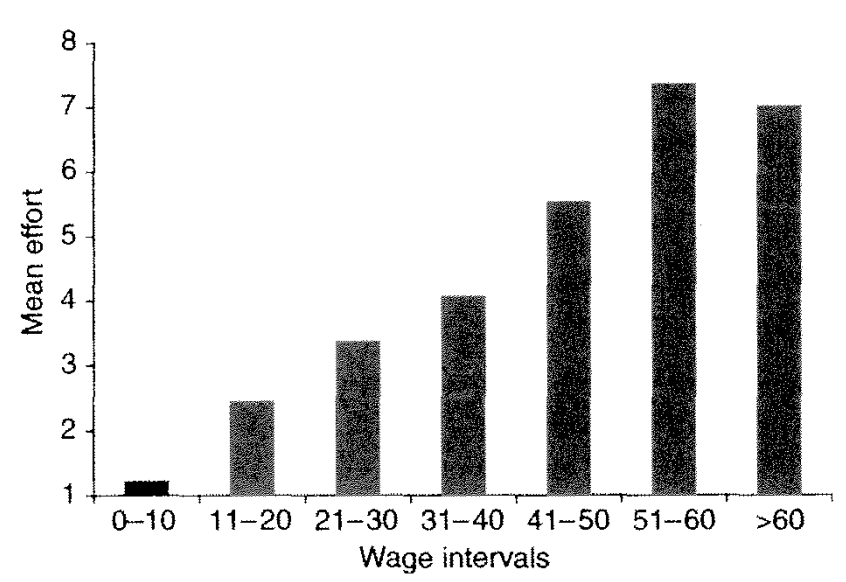

FIG. 3.6. Effort-wage relation in the gift exchange game

Source: Fehr, Gächter, and Kirchsteiger (1997).

are willing to put forward extra effort above what is implied by purely pecuniary considerations.

Similar to the Ultimatum Game the regularities in the gift exchange game are quite robust with regard to stake levels. In experiments in which subjects earned on average between two and three times their monthly incomes the same wage and effort patterns prevail. Another important result is obtained if there is competition between the workers--similar to the responder competition in the Ultimatum Game. While in the Ultimatum Game with responder competition proposers make much lower offers compared to the bilateral case, competition has no impact on wages in the gift exchange game. The reason for this striking result is that it does not pay for employers to push down wages because reciprocal workers respond to lower wages with lower effort levels.

\section{Third-party punishment games}

Many small scale societies are characterized by extensive foodsharing. A simple game to examine whether food sharing is a social norm that is enforced by social sanctions has been conducted by Fehr and Fischbacher $(2001 a)$. The game is called 'third-party punishment game' and has three players. The game between player A and player B is just a Dictator Game. Player A receives an endowment of 100 tokens of which he can transfer any amount to player $\mathrm{B}$, the recipient. Player $\mathrm{B}$ has no endowment and no choice to make. Player $C$ has an endowment of fifty tokens and observes the transfer of player A. After this player C can assign punishment points to player $A$. For each punishment point assigned to player $A$ player $\mathrm{C}$ has costs of one token and player $\mathrm{A}$ has costs of three tokens. Since punishment is costly a self-interested player $\mathrm{C}$ will never punish. However, if there is a sharing norm player $\mathrm{C}$ may well punish player $\mathrm{A}$ if $\mathrm{A}$ gives too little.

In fact, in the above experiments player $A$ is never punished if they transferred fifty or more tokens to player B. If they transferred less than fifty tokens the punishment was stronger, the less player $\mathrm{A}$ transferred. In case that player A transferred nothing she received on average nine punishment points from player $C$, that is, the payoff of player $A$ was reduced by twenty-seven tokens. This means that in this three-person game it was still beneficial, from a selfish point of view, for player A to give say, nothing compared to an equal split. If there is more than one player $\mathrm{C}$, who can punish player $\mathrm{A}$, this may, however, no longer be the case.

Another interesting question is to what extent cooperation norms are sustained through the punishment of free riders by third parties. We have already seen that in the Public Goods Game with punishment strikingly high cooperation rates can be enforced through punishment. In this game each contribution to the public good increases the payoff of each group member by 0.4 . Thus, if a group nember free rides instead of cooperation she directly reduces the other group members' payoff. In real life there are, however, many situations in which free riding has a very low, indeed almost imperceptible, impact on the payoff of particular other individuals. The question then is, whether these individuals nevertheless help enforcing a social norm of cooperation. In case they do a society greatly magnifies its capability of enforcing social norms because every member of a society acts as a potential policemen.

It is relatively easy to construct cooperation games with punishment opportunities for third (unaffected) parties. Fehr and Fischbacher (2001a), for example, have conducted Prisoner's Dilemmas in which a member of the two-person group, who played the Prisoner's Dilemma, observes a member of some other group, who also played the Prisoner's Dilemma. Then the member of the first group can punish the member of the second group. Thus, each member could punish and could be punished by somebody outside 
their own two-person group. It was ensured that reciprocal punishment was not possible, that is, if subject A could punish subject $\mathrm{B}$, subject $\mathrm{B}$ could not punish $\mathrm{A}$ but only some third subject $\mathrm{C}$. It turns out that the punishment by third parties is surprisingly strong. It is only slightly weaker than second-party (within group) punishment.

\section{THEORIES OF SOCIAL PREFERENCES}

Within economics, the leading explanation for the patterns of results described above is that agents have social preferences (or 'social utility') which take into account the payoffs and perhaps intentions of others. Roughly speaking, social preference theories assume that people have stable preferences for how money is allocated (which may depend on who the other player is, or how the allocation came about), much as they are assumed in economics to have preferences for food, the present versus the future, how close their house is to work, and so forth. ${ }^{11}$

Cultural anthropologists and evolutionary psychologists have sought to explain the origin of these preferences. One idea is that in the Environment of Evolutionary Adaptation or ancestral past. people mostly engaged in repeated games with people they knew. Evolution created specialized cognitive heuristics for playing repeated games efficiently. It is well-known in game theory that behavior which is optimal for a self-interested actor in a one-period game with a stranger - such as defecting or free riding, accepting all ultimatum offers - is not always optimal in repeated games with partners. In a repeated Ultimatum Game, for example, it pays to reject offers to build up a reputation for being hard to push around, which leads to more generous offers in the future. In the unnatural habitat view, subjects cannot 'turn off' the habitual behavior shaped by repeated game life in the Environment of Evolutionary Adaptation when they play single games with strangers in the lab. An

"I A different interpretation is that people have rules they obey about what to to such as, share money equally if you haven't earned it (which leads to equal-split offer in the Ultimatum Game) (Güth 1995). A problem with the rule-based approach is that subjects do change their behavior in response to changes in payoffs, in predictable ways. For example, when the incremental payoff from defecting against a cooperator (denoted $\mathrm{T}-\mathrm{H}$ above) is higher, people defect more often. When a player's benefit $m$ of the public good is higher, they contribute more. When the social return from investing in a tust game is lower, they invest less. Any rule-based account must explain why the rules are bent by incentives. A theory with flexible rules will probably end up looking like a theory of social preferences which explicitly weighs self-interest against other dimensions. important modification of this view is that evolution did not equip all people with identical hard-wired instincts for playing games, but instead created the capacity for learning social norms. The latter view can explain why different cultures would have different norms.

As is common in evolutionary explanations, the unnatural habitat theory assumes the absence of a module or cognitive heuristic that could have evolved but did not-namely, the capacity to distinguish temporary one-shot play from repeated play. If subjects had this ability they would behave appropriately in the one-shot game. In principle it is testable whether people have the ability to distinguish temporary one-shot play from repeated play. Fehr and Fischbacher (2003) did this in the context of the Ultimatum Game (cf. Camerer et al. 2002, in repeated Trust Games).

They conducted a series of ten Ultimatum Games in two different conditions. In both conditions subjects played against a different opponent in each of the ten iterations of the game. In each iteration of the baseline condition the proposers knew nothing about the past behavior of their current responders. Thus, the responders could not build up a reputation for being 'tough' in this condition. In contrast, in the reputation condition the proposers knew the full history of the behavior of their current responders, that is, the responders could build up a reputation for being 'tough'. In the reputation condition a reputation for rejecting low offers is, of course, valuable because it increases the likelihood to receive high offers from the proposers in future periods.

If the responders understand that there is a pecuniary payoff from rejecting low offers in the reputation condition one should observe higher acceptance thresholds in this condition. This is the prediction of the social preferences approach that assumes that subjects derive utility from both their own pecuniary payoff and a fair payoff distribution. If, in contrast, subjects do not understand the logic of reputation formation and apply the same habits or cognitive heuristics to both conditions, one should observe no systematic differences in responder behavior across conditions. Since the subjects participated in both conditions, it was possible to observe behavioral changes at the individual level. It turns out that the vast majority (slightly more than 80 percent) of the responders increase their acceptance thresholds in the reputation condition relative to the baseline condition. This contradicts the hypothesis that subjects do not understand the difference between one-shot and repeated play. 
The above experiment informs us about the proximate mechanisms that drive responder behavior in the Ultimatum Game. Whatever the exact proximate mechanisms will turn out to be, a hypothesis that is based on the story that subjects do not really understand the difference between one-shot and repeated play seems to be wrong. A plausible alternative hypothesis is that responders face strong emotions when faced with a low offer and that these emotions trigger the rejections. These emotions may be the result of repeated game interactions in our ancestral past and may not be fine-tuned to one-shot interactions. For modeling purposes, behaviorally relevant emotions can be captured by appropriate formulations of the utility function. This is exactly what theories of social preferences do.

The challenge for all the social preference theories (and evolutionary explanations of their origins) is to explain a lot of results in different games with one model, and make new predictions which survive attempts at falsification. For example, why players contribute in the standard Public Goods Game at first, then stop contributing; why they punish and contribute in the Public Goods Game with punishment opportunities; why responders reject unfair offers; why proposers in the Dictator Game give away money; why many trustees repay trust; why third parties punish defection in the Prisoner's Dilemma and unfair allocations in the Dictator Game and why competition causes more unequal divisions in Ultimatum Games but has no impact in gift exchange games.

Two flavors of models have been proposed---models of inequalityaversion and models of reciprocity. In inequality-aversion theories, players prefer more money and also prefer that allocations be more equal. Attempting to balance these two goals, players will sacrifice some money to make outcomes more equal. For example, in the theory of Fehr and Schmidt (1999), the players' goals are formalized as follows. Let $x_{i}$ denote the material payoff of player $i$ and $x_{j}$ the material payoff of player $j$. Then, the utility of player $i$ in a twoplayer game is given by $U_{i}(x)=x_{i}-\alpha_{i}\left(x_{j}-x_{i}\right)$ if player $i$ is worse off than player $j\left(x_{j}-x_{i} \geq 0\right)$, and $U_{i}(x)=x_{i}-\beta_{i}\left(x_{i}-x_{j}\right)$ if player $i$ is better off than player $j\left(x_{i}-x_{j} \geq 0\right) . \alpha_{i}$ is a constant that measures how much player $i$ dislikes disadvantageous inequality (envy) while $\beta$. measures how much $i$ dislikes advantageous inequality (guilt). When $\alpha_{i}$ and $\beta_{i}$ are zero players, $i$ is self-interested. Fehr and Schmidt also assume that, in general, players dislike advantageous inequality less

$\begin{array}{lcc} & \text { Cooperate (C) } & \text { Defect (D) } \\ \text { Cooperate (C) } & 2,2 & 0,3 \\ \text { Defect (D) } & 3,0 & 1,1\end{array}$

Tr. 3.7. Representation of Prisoner's Dilemma in terms of material payoffs

$\begin{array}{lcc} & \text { Cooperate (C) } & \text { Defect (D) } \\ \text { Cooperate (C) } & 2,2 & 0-3 \alpha, 3-3 \beta \\ \text { Defect (D) } & 3-3 \beta, 0-3 \alpha & 1,1\end{array}$

FiG. 3.8. Utility representation of Prisoner's Dilemma in Figure 3.7

than disadvantageous inequality, that is, $0 \leq \beta_{i} \leq \alpha_{i}$ and $\beta_{i}<1$. For $\alpha_{i}$ they assumed no upper bound. ${ }^{12}$

An important ingredient of this theory is that the population of players is assumed to be heterogeneous-some people act purely selfishly and some are inequality-averse. This model predicts all the regularities mentioned above: small offers in the Ultimatum Game are rejected by envious players with a positive $\alpha$ and positive allocations in Dictator Games occur when guilty players have a positive $\beta$. A positive $\beta$ also explains why trustees repay some money to investors in the trust game and why players who expect that the other player(s) cooperate in Prisoner's Dilemma and Public Goods Games reciprocate cooperation rather than defecting or free riding. The theory is consistent with the fact that in the Ultimatum Game with responder competition the responders reject much less than in the bilateral Ultimatum Game and why, in the gift-exchange game, responder competition does not matter. It also is consistent with (third party) punishment in the Prisoner's Dilemma, the Dictator Game and the Public Goods Game. For a quick illustration, consider the Prisoner's Dilemma in Figure 3.7. Note that the numbers in Figure 3.7 represent material payoffs and not utilities.

In Figure 3.8 we show the utilities that are attached with the material payoffs of Figure 3.7 if both players have identical preferences with $\alpha>0$ and $\beta>0$. In Fehr and Schmidt's theory, if player 2 (the column player) is expected to cooperate, player 1 (the

${ }^{12}$ In the general $n$-person case the utility function of Fehr and Schmidt is given by $U_{i}(x)=x_{i}-\alpha_{i} \frac{1}{n-1} \sum_{i \neq i} \max \left\{x_{i}-x_{i}, 0\right\}-\beta_{i} \frac{1}{n-1} \sum_{i t_{i}} \max \left\{x_{i}-x_{j}, 0\right\}$. The term $\max \left\{x_{j}-x_{i}, 0\right\}$ denotes the maximum of $x_{j}-x_{i}$ and 0 . It measures the extent to which there is disadvantageous inequality between player $i$ and $j$. 
row player) faces a choice between material payoff allocations $(2,2)$ and $(3,0)$. The social utility of $(2,2)$ is $U_{l}(2,2)=2$ because there is no inequality. The social utility of $(3,0)$, however, is $U_{I}(3,0)=3-3 \beta$ because there is inequality that favors the row player. Therefore, player 1 will reciprocate the expected cooperation of player 2 if $\beta>\frac{1}{3}^{13}$ (i.e. if player 1 feels sufficiently 'guilty' from defecting). If player 1 defects and player 2 cooperates, the payoff of player 2 is $U_{2}(3,0)=0-3 \alpha$ : if player 2 defected instead the utility would be 1 . This means that player 2 will always reciprocate defection because cooperating against a defector yields less money and more envy. ${ }^{14}$ Figure 3.8 shows that if $\beta>1 / 3$, there are two (mutual best response) equilibria: (cooperate, cooperate) and (defect, defect). In utility terms, inequality-averse players no longer face a Prisoner's Dilemma. Instead, they face a coordination or assurance game with one efficient and one inefficient equilibrium (the same as the "stag hunt' game described below). If the players believe that the other player cooperates, it is rational for each of them to cooperate, too.

Inequality-averse players are thus conditional cooperators. They cooperate in response to (expected) cooperation and defect in response to (expected) defection. The theory is, therefore, also consistent with framing effects in the Prisoner's Dilemma (and in Public Goods Games). If the framing of the game makes players more optimistic about the other players' cooperation, then inequalityaverse players will cooperate more.

Inequality-aversion theories are simplified because they include only the other players' material payoffs into the calculation of social utility. Reciprocity theories include other players' actions and, in particular, the intention behind the action, as well. In one important formal reciprocity theory (Rabin 1993), player A forms a judgment about whether another player B has sacrificed to benefit (or harm) her. A likes to reciprocate, repaying kindness with kindness, and meanness with vengeance.

${ }^{13}$ Note that if the temptation payoff is raised from 3 to $T$, then a player cooperates if $\beta>(T-2) / T$. Since the latter expression converges to 1 as $T$ grows larger, a player with a fixed $\beta$ who cooperates at a $T$ near 2 will switch to defection at some point as $T$ grows large; so the model predicts the correct (empirically observed) response to the change in payoff structure.

if This also means that if a selfish and an inequality-averse player are matched, and the inequality-averse player knows that the other player is selfish, the unique equit brium is (defect, defect). The reason is that the inequality-averse player knows that the other player will defect and, hence, she will defect, too.
In the Prisoner's Dilemma Figure 3.7, for example, suppose the row player is planning to cooperate. Then the column player's choice essentially determines what the row player will get. Since row's possible payoffs are 2 and 0 , let's take the average of these, 1 , to be a 'fair' payoff. By choosing to cooperate, the column player awards' the row player the payoff of 2 , which is 'nice' because it's greater than the fair payoff of $1 .{ }^{15}$ Rabin proposes a utility function in which niceness has a positive value and meanness has a negative value, and players care about their own dollar payoffs and the product of their own niceness and the niceness of the other player. Thus, if the other player is nice (positive niceness), they want to be nice too, so the product of nicenesses will be positive. But if the other player is mean (negative niceness), they want to be negative, too, so the product of nicenesses will be positive. While Rabin's theory is more analytically difficult than other theories, it captures the fact that a single player may behave nicely or meanly depending on how they expect to be treated-it locates social preferences and emotions in the combination of a person, their partner, and a game, rather than as a fixed personal attribute.

There are also hybrid models that combine the notions of reciprocity with models of social preferences based on own and other players' material payoffs. Charness and Rabin (2002) proposed a hybrid model in which players care about their own payoffs, and about a weighted average of the lowest payoff anybody receives (a 'Rawlsian' component) and the sum of all payoffs (a 'utilitarian' component). Their theory has a hidden aversion to inequality through the emphasis on the lowest payoff. In addition, players also care about the actions of the others. Falk and Fischbacher (1998) proposed a model that combines reciprocity and inequality aversion. Both the model of Charness and Rabin and of Falk and Fischbacher explain some data that Fehr-Schmidt's theory cannot explain. This increase in explanatory power comes, however, at a cost because these models are considerably more complicated.

There are an increasing number of experiments that compare predictions of competing theories. One important result of these experiments is that there is clear evidence for reciprocity beyond inequality-aversion (as anticipated by Rabin 1993). Players do not

The degree of niceness is formalized by taking the difference between the awarded and fair payoffs, normalized by the range of possible payoffs. In this example, niceness is $(2-1) /(2-0)=\frac{1}{2}$. 
only care about the allocation of material payoffs. They also care about the actions and the intentions of the other players.

Regardless of which models are most accurate, psychologically plausible, and technically useful, the important point for social scientists is that a menu of games can be used to measure social preferences, like the extent to which people weigh their monetary self-interest with the desire to reciprocate (or limit inequality), both negatively (in Ulimatum Games) and positively (in Trust Games), and with pure altruism (in Dictator Games). Dozens of experiments in many developed countries, with a wide range of instructions, subjects, and levels of stakes, have shown much regularity. And simple formal theories have been proposed which can account for findings that appear to be contradictory at first blush (e.g. sacrificing money to harm somebody in an Ultimatum Game, and sacrificing to help somebody in Prisoner's Dilemma or Trust Games). Exploring behavior in these games in a much wider range of cultures, at various stages of economic development and with varying patterns of sharing norms, governance structures, and so forth, will undoubtedly prove interesting and important. In addition, anthropological studies in remote field sites will serve as an important empirical reminder for economists and psychologists who currently study these games about how very narrow the range of cultures they study is.

\section{WHY DO GAME EXPERIMENTS? AND WHICH GAMES?}

A central advantage of experimental games is comparability across subject pools (provided great care is taken in controlling for differences in language, purchasing power of outcomes, interactions with experimenters, and so forth). While comparability is clearly not perfect, it is surely as good as most qualitative measures. A further advantage is replicability. The fact that experiments are replicable is a powerful tool for creating consensus about the fact and their interpretation in the scientific community.

In fact, experiments conducted in the field by anthropologists may actually have two large advantages compared to lab experiments in Western countries that usually (though not always) use college students as experimental subjects. First, since anthropologists are in the field for long periods of time, the cost of collecting data is rather low. (Most contributors to this volume often noted that the experiment was unusually fun for participants, probably more so than for college students raised in a world of Nintendo, 500-channel cable TV, and web surfing.) Second, the amount of funds budgeted by granting agencies in developed countries for subject payments typically have extraordinary purchasing power in small-scale societies. As a result, it is easy for anthropologists to test whether people behave differently for very large stakes, such as a week or month of wages, compared to low stakes. Such comparisons are important for generalizing to highstakes economic activity, but are often prohibitively expensive in developed countries.

Games impose a clear structure on concepts that are often vague or fuzzy. Social scientists often rely on data like the General Social Survey, in which participants answer questions such as, 'In general, how much do you trust people?' on a 7-point Likert scale. It would be useful to have questions about trust that are more concrete, tied to actual behavior, and likely to be interpreted consistently across people (see Glaeser et al. 2000). A question like 'How much of $\$ 10$ would you place in an envelope, knowing it will be tripled and an anonymous person will keep as much as they like and give the rest back to you?' is arguably a better survey question - it is more concrete, behavioral, and easy to interpret. Note that anthropologists also study their subjects much more carefully than experimental psychologists and economists do, so they often have lots of behavioral data to correlate with behavior from experimental games.

of course, games are reductions of social phenomena to something extremely simple, but they can always be made more complex. A painter who first sketches a line drawing on a blank canvas has reduced a complex image to two dimensions of space and color. But the line drawing reduction is also a platform on which more complex images can be restored (e.g. it can be painted over to give the dimension of color and the illusion of depth).

From a technical point of view it is often useful to apply the so-called strategy method in experiments. In the Ultimatum Game, for example, a strategy for the responder stipulates a Yes or No response for each possible offer. A simple way of eliciting a responder strategy is the elicitation of the responder's minimal acceptable offer, $x^{\min }$. If the actual offer is below $x^{\mathrm{min}}$, it is rejected, if it is above $x^{\min }$, it is accepted. This method has the big advantage that the experimenter not only knows the responder's response to 
the actual offer but also to all other feasible offers. Very often most offers in the Ultimatum Game are close to the equal split so that there are no rejections. In this case the experimenter learns little about the willingness to accept or reject low offers unless the strategy method is applied.

In simple societies the strategy method may sometimes be too complicated for the subjects. In this case it is advisable to restrict the set of feasible offers. For example, in the Ultimatum Game the experimenter may only allow a $90: 10$ offer and a $50: 50$ offer, and the responder then has to indicate his response to both potential offers before he knows the actual offer. For similar reasons as in the Ultimatum Game, the strategy method, is of course, also useful in many other games like, for example, the trust or the third party punishment game. Knowing the trustee's response to all feasible investments in the Trust Game, or player C's punishment of player A for all feasible transfers player A can make to player B in the third-party punishment game, provides a lot more information compared to the usual method.

The experimental games described in this chapter are line drawings, to which richness can be added. For example, most of the games we described are only played once without communication (the soundtrack of life is muted) and without mutual identification of who the other players are (like the Magritte painting 'The Lovers' in which two people kiss with their heads shrouded in cloth). Conducting experiments this way is obviously not a deliberate choice to model a world in which people don't talk and only meet hooded strangers (although it might be appropriate for nearly anonymous internet transactions). Instead, this baseline design is a stark control condition that can be used to study the effect of communication, by comparing results in the control condition with experiments in which communication is allowed (turning up the soundtrack volume) and mutual identification is allowed (removing the hoods).

Other games social scientists might find useful

While the games described above have been studied most widely (including by anthropologists; see this volume) other games or treatments might also be of interest. This section describes four of them.

$$
\begin{array}{lcc} 
& \text { Stag } & \text { Rabbit } \\
\text { Stag } & 2,2 & 0,1.5 \\
\text { Rabbit } & 1.5,0 & 1,1
\end{array}
$$

Fro. 3.9. The 'stag hunt' or assurance game

Measuring moral authority in dictator games As noted above, the Dictator Game is a weak situation in the sense that a wide variety of treatment variables -instructions, entitlement, experimental control for 'blindness' to individual allocations, identification of recipients, etc.--affect allocations significantly. The fact that preferences are malleable suggests a way to measure moral authority, which was very cleverly suggested by Carolyn Lesorogol. Collect a group of subjects. Have a person A suggest a way the subjects should play the Dictator Game. Then have the subjects play. The extent to which subjects adhere to A's recommendation is a measure of A's moral authority or ability to create norms which are adhered to. (Lesorogol used this method to see whether traditional anthority, of village elders, had declined after land privitization.)

Coordination: Assurance and threshold public goods games Figure 3.9 shows a game called 'stag hunt', also known as an 'assurance game' or Wolf's Dilemma. The game is identical to the Prisoner's Dilemma in structure except for one crucial difference: It is better to reciprocate cooperation, because the material payoff to defecting when the other player cooperates is lower than the material payoff from cooperating. If there are strong synergies or 'complementarities' from the cooperative choices of two players, or if free riders are punished after they defect, then the Prisoner's Dilemma game is transformed into stag hunt. ${ }^{16}$

The game is called stag hunt after a story in Jean-Jacques Rousseau about hunters who can choose to hunt a large stag with others, which yields a large payoff if everyone else helps hunt the stag, or can hunt for rabbit on their own. An example familiar to anthropologists is hunting for large animals like whales (see Alvard,

${ }^{16}$ Recall that when players are inequality-averse the PD, when represented in social utility terms, is transformed into an assurance game. From an experimental viewpoint, this is, however, different from an assurance game where the payoffs are monetary. While the experimenter has full control over the monetary payoffs we can never be sure about the preferences of the players. 
Chapter 14 , this volume), in which the marginal hunter's presence can be crucial for a successful hunt. Stag hunt is a 'coordination game' because there is more than one Nash equilibrium, and players would like to find a way to coordinate their choices on one equilibrium rather than mismatch. Since stag is a best-response to hunting stag, (stag, stag) is an equilibrium; but so is (rabbit, rabbit).

Stag hunt is closely related to 'threshold' Public Goods Games (also called the 'volunteer's dilemma'). In these games there is a threshold of total contribution required to produce the public good. If $n-1$ players have contributed, then it pays for the $n$th player to pitch in and contribute, since her share of the public good outweighs the cost of her marginal contribution.

The central feature of the Prisoner's Dilemma is whether the other player has social preferences that induce her to cooperate (acting against her self-interest) and whether the player himself gets social utility from reciprocating cooperation. Stag hunt is different: because players get a higher material payoff from reciprocating the cooperative choice (stag), all they need is sufficient assurance that others will hunt stag (i.e. a probability of playing stag above $\frac{2}{3}$. which makes the expected payoff from stag higher than the expected payoff from rabbit) to trigger their own stag choice. The Prisoner's Dilemma game is about cooperativeness; how cooperative is player 1 and how cooperative does he expect player 2 to be. Stag hunt is solely about perceptions of whether others are likely to cooperate. Experiments with coordination games like stag hunt show that, perhaps surprisingly, the efficient (stag, stag) outcome is not always reached. Preplay communication helps. Social structure has an interesting effect: if a population of players are matched randomly each period, the tendency to play stag is higher than if players are arrayed on a (virtual) circle and play only their neighbors each period. Stag hunt could be useful to measure whether a culture has a norm of playing 'stag' when the cooperative action is risky.

Status in bargaining Figure 3.10 shows a game called 'battle of the sexes'. In this game, two players simultaneously choose a strategy

$\begin{array}{lll} & \mathrm{R} & \mathrm{C} \\ \mathrm{R} & 3,1 & 0,0 \\ \mathrm{C} & 0,0 & 1,3\end{array}$

FIG. 3.10. Battle of the Sexes Game we have labeled $\mathrm{R}$ and $\mathrm{C}$. If the players mismatch, they get nothing. If they match on $\mathrm{R}$, the row player gets the higher payoff of 3 and the column player gets 1 . The payoffs are opposite if they match on $C$. The game is called battle of the sexes after a hoary story about a husband and wife who would like to attend an event together, but the husband prefers boxing while the wife prefers ballet.

Battle of the sexes is a classic 'mixed-motive' game because the players prefer to agree on something than to disagree, but they disagree on what to agree on. Alternatively, think of the game as a bargaining game in which the players will split 4 if they can agree how to split it (but it must be uneven, $3: 1$ or $1: 3$ ) and earn nothing otherwise.

In experiments with payoffs like Figure 3.10, players tend to choose their preferred strategy (row chooses $\mathrm{R}$, column chooses $\mathrm{C}$ ) around 65 percent of the time, which means they mismatch more than half the time (see Camerer 2003: ch. 7). Since mismatches yield nothing, the game cries out for some social convention or coordinating device which tells players which one of them gets the larger payoff; in principle, the player who gets less should go along with the convention since getting 1 is better than mismatching and getting nothing.

Any commonly understood variable which produces consistent matches in a pair of players can be interpreted as an indicator of status. A striking illustration of this is Holm's (2000) experiments on battle of the sexes and gender. He ran experiments in which men and women played battle of the sexes games (simultaneously, with no communication) with players of the same sex and opposite sex. Take the row player's view. When women played with men, the women (in the row player position) were more likely to play $\mathrm{C}$ and men (in the row player position) where more likely to play $\mathrm{R}$, compared to when they played with subjects of the same gender. The players played as if they all respected a social convention in which women get the smaller share and the men the larger share. Remarkably, women actually earned a larger average payoff playing against men than playing against other women! The reason for this is that earning 1 with a high probability is better than trying to earn 3 but mismatching very frequently.

We interpret these results as evidence that males have status. An agreed-upon status variable has two interesting effects in these 
games: It increases collective gains (by minimizing mismatches); and it creates greater wealth for the high-status group than for the lowstatus group. The latter effect, of course, can spark a self-fulfilling spiral in which, if wealth itself creates status, the rich get status and get richer, too. ${ }^{17}$

Since concepts of hierarchy, privilege, and status are central in anthropology (and in sociology), games like battle of the sexes which reveal status relations (and show their economic impact) could prove useful. Game-theoretic revelation of status also provides a way for economists to comprehend such concepts, which do not fit neatly into primitive economic categories like preferences and beliefs.

Shared understanding and cultural homogeneity in matching games In 1960, Schelling drew attention to simple 'matching games', in which players choose an object from some category, and earn a fixed prize if their objects match. For example, subjects who are asked to choose a place and time to meet in New York City often choose noon at Grand Central Station, or other prominent landmarks like Central Park or the Statue of Liberty. Careful experiments by Mehta, Starmer, and Sugden (1994) show the same effect. Asked to name a mountain, 89 percent of subjects picked Mt Everest; naming a gender, 67 percent picked 'man'; naming a relative, 32 percent picked 'mother' ( 20 percent picked 'father'); asked to pick a meeting place in London, 38 percent picked Trafalgar Square; and so forth.

From a game-theoretic viewpoint, matching games with a large choice set have lots and lots of equilibria. Schelling's point was that shared world knowledge often picks out a psychologically prominent 'focal' point. A focal point is the right choice if 'everybody knows' it's the right choice. The extent of shared understanding can be measured by how well subjects match. We suggest this as a measure of cultural homogeneity. For example, Los Angeles is a diverse patchwork of local communities of wildly varying ethnicity. Asked to choose a meeting place in LA (playing the game with their own ethnic or geographical community), Koreans might choose the

\footnotetext{
17 An alternative interpretation is that Battle of Sexes play reflects the extent to which the aggressiveness of the other player is common knowledge. If all women believe that men are more aggressive, it pays for them to give in. Yet, if wealth creates status, than the greater aggressiveness of men ultimately also confers status.
}

corner of Western and Wilshire (the heart of 'Koreatown'), those from south beach might choose 'The Strand' (a boardwalk by the ocean), Hollywood Hills trendies would choose Skybar, and so forth. The fact that most readers haven't heard of all these 'famous' places is precisely the point. The degree to which a group coordinates on a culturally understood meeting place seems like a good measure of overall cultural homogeneity. (If they do not agree, they aren't a group--at least not a group with shared cultural knowledge.)

Weber and Camerer (2003) use matching games, with a linguistic twist, to study endogenous development of culture and cultural conflict. In their experiments, a pair of subjects are each shown sixteen pictures which are very similar (e.g. scenes of workers in an office). One subject is told that eight of the pictures have been selected as targets. This subject, the director, must describe the pictures to the second subject, so that the second subject chooses the correct pictures as quickly as possible. (They earn money for accuracy and speed.) Since the subjects have never seen these pictures before, they must create a homemade language to label the pictures. Because they are under time pressure, with repeated trials they create a very pithy 'jargon' to describe the distinctive features of a picture as briefly as possible. Their homemade language is one facet of culture (albeit designed to accomplish a specific purpose-commonly understood labeling of novel objects). Cultural conflict can be studied by combining two separate groups, whose jargon tend to be different.

These paradigms can be used to measure or create shared understanding, with economic incentives to reveal shared understanding or create it quickly. These could prove useful in anthropology too for measuring cultural homogeneity and dimensions of shared perception.

\section{CONCLUSIONS}

Game theory has proved useful in a wide range of social sciences in two ways: by providing a taxonomy of social situations which parse the social world; and by making precise predictions about how selfinterested players will actually play. Behavior in experiments which carefully control players' strategies, information, and possible payoffs shows that actual choices often deviate systematically from 
the game-theoretic prediction based on self-interest. These deviations are naturally interpreted as evidence of social norms (what players expect and feel obliged to do) and social preferences (how players feel when others earn more or less money). This evidence is now being used actively by economists to craft a parsimonious theory of social preferences that can be used to explain data from many different games in a simple way that makes fresh predictions. Since anthropologists are often interested in how social norms and preferences emerge, evolve, and vary across cultures, these games could provide a powerful tool for doing empirical anthropology. In addition to measuring social preferences and social norms experimental games may also be used for measuring moral authority, players beliefs about other players' actions in coordination games, cultural homogeneity, and status effects in bargaining.

\section{REFERENCES}

Andreoni, James (1988). 'Why free ride? Strategies and learning in publie goods experiments', Journal of Public Economics, 37, 291-304.

- (1995). 'Warm-glow versus cold-prickle: the effects of positive and negative framing on cooperation in experiments', Quarterly Journal of Economics, $110,1-22$.

Berg, Joyce, Dickhaut, John, and McCabe, Kevin (1995). 'Trust, reciprocity and social history', Games and Economic Behavior, 10, 122-42.

Bohnet, Iris and Frey, Bruno S. (1999). 'Social distance and otherregarding behavior in dictator games: Comment', American Economic Review, 89 (March), 335--9.

Burks, Stephen, Carpenter, Jeffrey, and Verhoegen, Eric (2002). 'Comparing students to workers: The effect of stakes, social framing, and demographics on bargaining outcomes', Middlebury Working Paper. http://community.middlebury.edu/jcarpent/papers.html

Camerer, Colin F. (2003). Behavioral Game Theory: Experiments on Strategic Interaction. Princeton, NJ: Princeton University Press.

- and Ho, Teck (1999). 'Experience-weighted attraction (EWA) learning in normal-form games', Econometrica, 67, 827-74.

Chong, Kuan, and Weigelt, Keith (2002). 'Strategic teaching and equilibrium models of repeated trust and entry games', Caltech working paper, October.

http://www.hss.caltech.edu/camerer/camerer.html

- and Weigelt, Keith (1988). 'Experimental tests of a sequential equilibrium reputation model', Econometrica, 56, 1-36.
Charness, Gary and Rabin, Matthew (2002). 'Understanding social preferences with simple tests', Quarterly Journal of Economics, 117, 817-69.

Croson, Rachel T. A. (1999). 'Theories of altruism and reciprocity: Evidence from linear public goods games', Discussion Paper, Wharton School, University of Pennsylvania.

Davis, Douglas and Holt, Charles (1993). Experimental Economics. Princeton, NJ: Princeton University Press.

Dawes, Robyn M. (1980). 'Social dilemmas', Annual Review of Psychology, 31, 169-93.

Falk, Armin and Fischbacher, Urs (1998). A Theory of Reciprocity, Institute for Empirical Research in Economics, University of Zurich, Working Paper No. 6.

Fehr, Ernst and Fischbacher, Urs (2001a). Third Party Norm Enforcement, Institute for Empirical Research in Economics, University of Zurich, Working Paper No.106. http://www.unizh.ch/iew/wp/iewwp106.pdf

(2003). 'The nature of human altruism-proximate patterns and evolutionary origins', Nature (in press).

Gächter, Simon, and Kirchsteiger, Georg (1997). 'Reciprocity as a contract enforcement device', Econometrica, 65, 833-60.

- and Gächter, Simon (2000). 'Cooperation and punishment in public goods experiments', American Economic Review, 90, 980--94. and Schmidt, Klaus M. (1999). 'A theory of fairness, competition and co-operation', Quarterly Journal of Economics, 114, 817--68.

- Kirchsteiger, Georg, and Riedl, Arno (1993). 'Does fairness prevent market clearing? An experimental investigation', Quarterly Journal of Economics, CVIII, 437-60.

Fischbacher, Urs, Fong, Christina, and Fehr, Ernst (2003). Fairness and the Power of Competition, Institute for Empirical Research in Economics, University of Zurich, Working Paper No. 133. http://www.unizh.ch/iew/wp/iewwp133.pdf

_- Gächter, Simon, and Fehr, Ernst (2001). 'Are People Conditionally Cooperative? -Evidence from Public Goods Experiments', Economic Letters, 71, 397-404.

Forsythe, Robert L., Horowitz, Joel, Savin, N. E., and Sefton, Martin (1994). 'Fairness in simple bargaining games', Games and Economic Behavior, 6, 347-69.

Frey, Bruno and Bohnet, Iris (1997). 'Identification in democratic society', Journal of Socio-Economics, 26, 25-38.

Friedman, Daniel and Sunder, Shyam (1994). Experimental Methods-A Primer for Economists. Cambridge: Cambridge University Press.

Fudenberg, Drew and Levine, David (1998). The Theory of Learning in Games. Cambridge, MA: MIT Press. 
Glaeser, Edward, Laibson, David, Scheinkman, Jose, and Soutter. Christine (2000). 'What is social capital? The determinants of trusi and trustworthiness', Quarterly Journal of Economics, 115, 811-46.

Güth, Werner, Schmittberger, Rolf, and Schwarze, Bernd (1982). An experimental analysis of ultimatum bargaining', Journal of Economile Behavior and Organization, III, 367-88.

- (1995). 'On the construction of preferred choices-The case of ultimatum proposals', Discussion Paper Economic Series No. 59. Humboldt University Berlin.

Hill, Elisabeth and Sally, David (2002). Dilemmas and Bargains: Theort: of-Mind, Cooperation, and Fairness. University College London Working Paper.

Hoffman, Elisabeth, McCabe, Kevin, and Smith, Vernon (1994). Pre ferences, property rights, and anonymity in bargaining games, Games and Economic Behavior, 7, 346-80.

(1996). 'On expectations and monetary stakes in ultimatum games', International Journal of Game Theory, 25, 289-301.

Holm, Hakan J. (2000). 'Gender Based Focal Points', Games and Leonomic Behavior, 32(2), 292-314.

Isaac, Mark R., Walker, James M., Williams, Arlington W. (1994). 'Group size and the voluntary provision of public goods', Joumal of Public Economics, 54, 1-36.

- McCue, Kenneth F., and Plott, Charles R. (1985). 'Public goods provision in an experimental environment', Journal of Public Economics, 26, 51--74.

Kahneman, Daniel, Knetsch, Jack L., and Thaler, Richard (1986) 'Fairness as a constraint on profit seeking: Entitlements in the market'. American Economic Review, 76, 728-41.

Knack, Steven and Keefer, Philip (1997). 'Does social capital have an economy payoff? A cross-country investigation', Quarterly Joumal of Economics, $112,1251-88$.

Ledyard, John (1995). 'Public goods: A survey of experimental research'. in Alvin Roth and John Kagel (eds), Handbook of Experimental Dro nomics, Princeton, NJ: Princeton University Press.

Mehta, Judith, Starmer, Chris, and Sugden, Robert (1994). 'The nature of salience-an experimental investigation in pure coordination games. American Economic Review, 84, 658-73.

North, Douglass (1990). Institutions, Institutional Change and Economic Performance. Cambridge: Cambridge University Press.

Ostrom, Elinor (2000). 'Collective action and the evolution of social norms', Journal of Economic Perspectives, 14, 137-58.

Rabin, Matthew (1993). 'Incorporating fairness into game theory and economics', American Economic Review, 83(5), 1281-302.

Ross, Lee and Ward, Andrew (1996). 'Naive realism in everyday life Implications for social conflict and misunderstanding', in E. S. Reed.
C. Turiel, and T. Brown (eds), Values and Knowledge, Mahwah, NJ: Erlbaum Associates, pp. 103-35.

Roun, Alvin E., Prasnikar, Vesna, Okuno-Fujiwara, Masahiro, and 7amir, Shmuel (1991). 'Bargaining and market behavior in Jerusalem, ijubljana, Pittsburgh, and Tokyo: An experimental study', American tonomic Review, 81, 1068-95.

Salv, David (1995). 'Conversation and cooperation in social dilemmas: A reta-analysis of experiments from 1958-1992', Rationality and Society, 2, $58-92$.

schelling, Thomas (1960). The Strategy of Conflict. Cambridge, MA: Harvard University Press.

Srith, Natalie (2000). 'Ultimatum and dictator games among the chaldeans of Detroit', Talk to MacArthur Foundation Anthropology Poject, December 4, 2000.

Neber, Roberto, and Camerer, Colin F. (2003). 'Cultural conflict and merger failure: an experimental approach', Management Science, 49(4), $.100-15$

Woibull, Jörgen (1995). Evolutionary Game Theory. Cambridge, MA: MIT Press.

Wlliamson, Oliver (1985). The Economic Institutions of Capitalism. New rork: Free Press.

Vamagishi, Toshio (1986). 'The provisioning of a sanctioning system as a public good', Journal of Personality and Social Psychology, 5, 110-16. 